\title{
Integrated vaccination and physical distancing interventions to prevent future COVID-19 waves
}

\section{Bo Huang ( $\sim$ bohuang@cuhk.edu.hk)}

Department of Geography and Resource Management, The Chinese University of Hong Kong, Hong Kong SAR https://orcid.org/0000-0002-5063-3522

\section{Jionghua Wang}

Department of Geography and Resource Management, The Chinese University of Hong Kong, Hong Kong SAR https://orcid.org/0000-0001-8265-3985

\section{Jixuan Cai}

Tencent Inc.

\section{Shiqi Yao}

Department of Geography and Resource Management, The Chinese University of Hong Kong, Hong Kong SAR https://orcid.org/0000-0003-0844-2973

\section{Paul Kay Sheung CHAN ( $\nabla$ paulkschan@cuhk.edu.hk)}

Department of Microbiology, Faculty of Medicine, The Chinese University of Hong Kong https://orcid.org/0000-0002-6360-4608

\section{Tony Hong wing TAM}

Department of Sociology, The Chinese University of Hong Kong

\section{Ying-yi Hong}

Department of Marketing, The Chinese University of Hong Kong

\section{Corrine W. Ruktanonchai}

WorldPop, School of Geography and Environmental Science, University of Southampton

\section{Alessandra Carioli}

WorldPop, School of Geography and Environmental Science, University of Southampton

\section{Jessica R. Floyd}

WorldPop, School of Geography and Environmental Science, University of Southampton Nick W. Ruktanonchai

WorldPop, School of Geography and Environmental Science, University of Southampton

\section{Weizhong Yang}

Chinese Academy of Medical Sciences \& Peking Union Medical College

\section{Zhongjie Li}

Chinese Center For Disease Control and Prevention

\section{Andrew J. Tatem ( $\square$ A.J.Tatem@soton.ac.uk)}

WorldPop, School of Geography and Environmental Science, University of Southampton https://orcid.org/0000-0002-7270-941X 


\section{Shengjie Lai}

WorldPop, School of Geography and Environmental Science, University of Southampton

\section{Research Article}

Keywords: Vaccination, physical distancing, social contact, mobility, population density

Posted Date: February 5th, 2021

DOI: https://doi.org/10.21203/rs.3.rs-208740/v1

License: (c) (1) This work is licensed under a Creative Commons Attribution 4.0 International License. Read Full License 
Original submitted version

(The latest version of this manuscript has been accepted for publication in Nature Human Behavior on January 27, 2021)

Integrated vaccination and physical distancing interventions to prevent future COVID-19 waves Hong-wing Tam $^{3}$, Ying-Yi Hong7 ${ }^{7}$, Corrine W. Ruktanonchai ${ }^{8,9}$, Alessandra Carioli ${ }^{8}$, Jessica R. Floyd $^{8}$, Nick W. Ruktanonchai ${ }^{8,9}$, Weizhong Yang ${ }^{10}$, Zhongjie Li $^{11}$, Andrew J. Tatem ${ }^{8}$, Shengjie $\mathrm{Lai}^{8,10,12+}$

Abstract: COVID-19 resurgences worldwide have posed significant challenges to the formulation of preventive interventions, especially given that the effects of physical distancing and upcoming vaccines on reducing susceptible social contacts and eventually halting transmission are still unclear. Using anonymized mobile geolocation data in China, we devised a mobility-associated social contact index to quantify the impact of both physical distancing and vaccination measures in a unified way such that the gap between intervention measures and disease transmission can be explicitly bridged. This index explained $90 \%$ of the variance in the changing reproduction number of infections across the COVID-19 outbreak in Wuhan, and was validated in six other cities of different population densities. Our simulations showed that vaccination combined with physical distancing can contain resurgences without relying on mobility reduction, whereas a gradual

\footnotetext{
${ }^{1}$ Department of Geography and Resource Management, The Chinese University of Hong Kong, Hong Kong SAR. ${ }^{2}$ Institute of Space and Earth Information Science, The Chinese University of Hong Kong, Hong Kong SAR. ${ }^{3}$ Department of Sociology and Center for Population Research, The Chinese University of Hong Kong, Hong Kong SAR. ${ }^{4}$ Tencent Inc., Shenzhen, China. ${ }^{5}$ Department of Microbiology, Faculty of Medicine, The Chinese University of Hong Kong, Hong Kong SAR. ${ }^{6}$ Stanley Ho Centre for Emerging Infectious Diseases, Faculty of Medicine, The Chinese University of Hong Kong, Hong Kong SAR. ${ }^{7}$ Department of Management, The Chinese University of Hong Kong, Hong Kong SAR. ${ }^{8}$ WorldPop, School of Geography and Environmental Science, University of Southampton, England, UK. ${ }^{9}$ Population Health Sciences, Virginia Tech, Blacksburg, VA 24061, USA. ${ }^{10}$ School of Population Medicine and Public Health, Chinese Academy of Medical Sciences \& Peking Union Medical College, Beijing, China. ${ }^{11}$ Division of Infectious Diseases, Chinese Center for Disease Control and Prevention, Beijing, China. ${ }^{12}$ School of Public Health, Fudan University, Shanghai, China. *E-mail: bohuang@cuhk.edu.hk; paulkschan@cuhk.edu.hk; A.J.Tatem@soton.ac.uk.
} 
vaccination process alone cannot achieve this. Further, for cities with medium-population density, vaccination can shorten the duration of physical distancing by $36 \%-78 \%$, whereas for cities with high-population density, infection numbers can well be controlled through moderate physical distancing. These findings provide guidance on tailoring and implementing comprehensive interventions for cities with varying population densities.

\section{Introduction}

Since the coronavirus disease (COVID-19) was first identified in December 2019 in Wuhan, $\mathrm{China}^{1}$, the entire world has been adversely affected by the ensuing pandemic ${ }^{2-4}$. As infections decreased during the summer (2020) months, many countries relaxed their lockdown and physical distancing measures in the course of reopening their economies and societies. Due to the increasing mobility and social contact rates, accompanied with the large numbers of susceptible people in the population, countries worldwide have been experiencing COVID-19 resurgences $^{5-7}$.

In the absence of an effective vaccine, physical distancing interventions (e.g., closure of schools and workplaces) are critical to contain the resurgences, even though such interventions have caused significant disruptions to societies and economies ${ }^{8}$. Policymakers are looking forward to the arrival of vaccines by late 2020 or early 2021 so that physical distancing interventions can be alleviated, as vaccination can reduce a portion of susceptible contacts that can potentially result in transmission. However, the extent of potential alleviation is still unclear, especially given that the supply of vaccines will likely not be sufficient to achieve herd immunity in the immediate future $^{9}$. Therefore, more comprehensive interventions including both physical distancing and vaccine implementation strategies should be developed to avoid COVID-19 resurgences ${ }^{10,11}$. To this end, there is an urgent need to understand the interrelationships among mobility, social contacts, physical distancing, vaccination, and virus transmission for tailoring and adjusting preventive interventions. 
Human movement and contact rates play fundamental roles in shaping the transmission patterns of infectious diseases ${ }^{12-18}$. Their impact on COVID-19 inter-city spread has been extensively investigated using anonymized mobile phone data ${ }^{19-23}$, and previous studies have attempted to assess the effects of travel and physical distancing measures on the first wave of the COVID-19 pandemic ${ }^{24-27}$ In addition, mobility data have been recognized as effective for reflecting resumed human activities after lifting lockdown measures ${ }^{24}$, and have also been used as a proxy for measuring the effectiveness of interventions, such as stay-at-home orders, to mitigate or contain the transmission of COVID-19 $9^{28-30}$. However, most studies have primarily used existing publicly available datasets to derive and provide coarse information on population mobility to measure changes in inter-city travel flow, check-in intensity, or trip length under interventions ${ }^{31-}$ 34. More refined data with anonymized geolocation information have been under-utilized to directly inform social contact rates ${ }^{21,24,25,32,35}$. The use of only mobility data would also not be able to facilitate assessing the impact of vaccination measures, which requires deriving information on safe social contacts in modeling transmission dynamics.

Because mobility data cannot directly inform physical distancing and reductions in contact rates, studies examining the effect of lockdown policies on transmission have generally assumed that when people reduce their mobility, they proportionally reduce their contacts ${ }^{17,18,24}$. However, in reality, similar levels of social contact have been observed at both high and low levels of mobility in various studies ${ }^{11,31-34}$, and using mobility or social contact data alone may not be sufficient for precisely measuring physical distancing. The paired relationship between reductions/restorations in mobility and social contacts is more suited to serve this purpose. Thus, it is crucial to understand the interaction between mobility and social contact rates over time under COVID-19 interventions.

Future studies on epidemic spread should be able to consider the strong interaction between physical distancing and mobility to reduce contact rates with or without vaccination in case of resurgences ${ }^{36}$. Ideally, investigation of the reduction in contact rates would involve creating a 
singular index that encompasses the combined impact of reduced mobility and physical distancing on contact rates so as to directly inform the estimates of contact levels among populations over time. This index should also be able to account for the impact of vaccination on reducing susceptible contact rates with minimal adaptations. In this paper, we propose a social contact index (SCI) to represent the daily average potential social contact (or spatiotemporal co-presence) per person, which was derived from an anonymized mobile geolocation dataset. The index associates a series of mobility levels (e.g., $10 \%$ to $100 \%$ with increments of $10 \%$ ) with their corresponding social contact rates. Based on this association, an empirical relationship was established using allometric equations ${ }^{37}$ to compute the contact rates under a given level of physical distancing and population density for future scenario simulations. As a proxy for daily social contact rates per person, this index was incorporated into a modified susceptible-exposed-infectious-recovered (SEIR) model to quantify the impact of physical distancing interventions in light of the COVID19 outbreak across China. The risks of COVID-19 resurgence under a no-vaccination scenario were then assessed under varying mobility, physical distancing, and population density scenarios. Subsequently, the effect of administering vaccines to relax physical distancing interventions and reduce unsafe social contacts was assessed in preventing a resurgence of infections and curtailing the pandemic.

\section{Deriving a social contact metric in populations}

The proposed SCI used to measure the level of contacts per person in a city was created using the total number of potential contact events (or the total social contacts index; TSCI), which was directly determined using a large, near-real-time anonymized mobile device positioning dataset that covers more than $70 \%$ of the population in mainland $\mathrm{China}^{30}$. In this dataset, the potential contact events are detected in the context of the spatiotemporal co-presence of people ${ }^{38-}$ 40 or when their mobile devices request positioning services within a specified space-time bin (i.e., 250 meters and 10 minutes in our case) (Extended Data Fig. 1 A). 
The SCI is an average per person TSCI. It is paired with mobility in a non-linear form (see Methods section "Social contact measurement" for more details), but is also influenced by physical distancing (Extended Data Fig. 1 B) and population density. Here, mobility refers to the number of trips people make outside their homes. During the COVID-19 outbreak, people might have been

Taking Wuhan as an example, an overview of the overall social contact rates, as reflected by the TSCI of the entire city, is provided, together with the changes in the TSCI before, during, and after the lockdown (January 23-April 9, 2020) due to the implementation of physical distancing measures of varying intensities (Fig. 1 A-C). The TSCI was categorized into five types based on the areas of interest ${ }^{34}$ where contact occurred, namely residential communities, workplaces, schools, shopping/recreation facilities, and other facilities. Before the lockdown (normal period) in December 2019, more than $80 \%$ of the contact occurred in the first four types of places. Fig. $1 \mathrm{D}$ shows the changes in the TSCI of Wuhan and those of four other major cities in China (Beijing, Shanghai, Guangzhou, and Shenzhen) against their normal patterns (the average levels in December 2019). After the implementation of nationwide interventions since January 23, 2020, the TSCI of the five cities decreased drastically, and especially that of Wuhan dropped to only $2 \%$ of its normal level (i.e., 1.016) on January 27 , i.e., the day 4 after imposing the lockdown measures. On April 8, the lockdown was lifted in Wuhan and the TSCI slowly recovered reaching $50 \%$ on May 31, while the TSCI values of other Chinese cities nearly returned to the respective normal levels (Fig. 1 D). 
As revealed by the variations in the SCI values shown in Fig. 1, physical distancing restrictions of varying intensities were imposed over different periods in Wuhan, namely prelockdown (e.g., December 2019), lockdown (from January 23 to April 9, 2020), shortly after lockdown lifting (SALDL) (from April 8 to May 20, 2020), and longer after lockdown lifting (LALDL) (from May 20 to May 30, 2020, after nucleic acid testing of all citizens) ${ }^{41,42}$. Various interventions were implemented together, which made it difficult to quantify their effects on the contact rate. To solve this problem, we derived four explicit sets of physical distancing interventions using the mobility dataset, namely "no," "mild," "moderate," and "strong" (see Methods section "Quantifying the relationship between mobility and social contacts" and Extended Data Table 1 for more details). Each set of these interventions at a certain intensity was found to cause similar impacts on the SCI values as those imposed together during the same period in Wuhan. This outcome allowed us to inform transmission dynamics under explicit sets of physical distancing measures.

The relationship between mobility and the SCI was modeled as an allometric growth curve 37 , but it varied over the three levels of population density and the four intensities of physical fitting each curve under a series of randomly sampled mobility levels were determined using the mobility dataset during the normal period (i.e., December 2019 in our case) because there was no significant population migration or physical distancing intervention. The modeled SCI values were validated against the actual SCI values extracted from the original dataset under each mobility level (see Methods section "Quantifying the relationship between mobility and social contacts" for details). Thus, a mobility-SCI coupled metric was formulated in the form of these equations to determine the SCI. This metric can also be adapted to evaluate the effect of vaccination on the SCI. As the people with immunity to SARS-CoV-2 cannot infect or be infected by others, their contacts would not impact the transmission process. This group of people can therefore be treated smartly in a way similar to mobility reduction. The empirical relationships were subsequently used in 
149 scenario-based simulations, which required the restored/reduced mobility (representing the levels 150 of reopening/reclosing economies), physical distancing, vaccination, and population density data 151 to derive contact rates.

152

153 


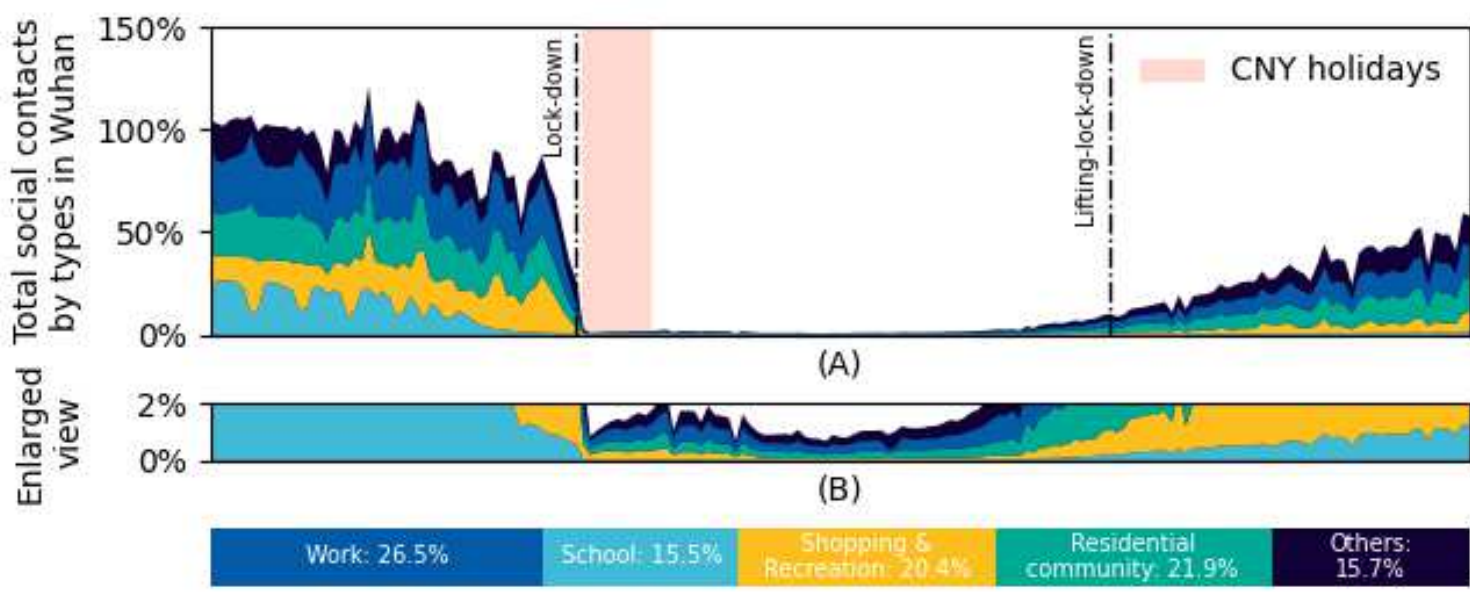

(C)

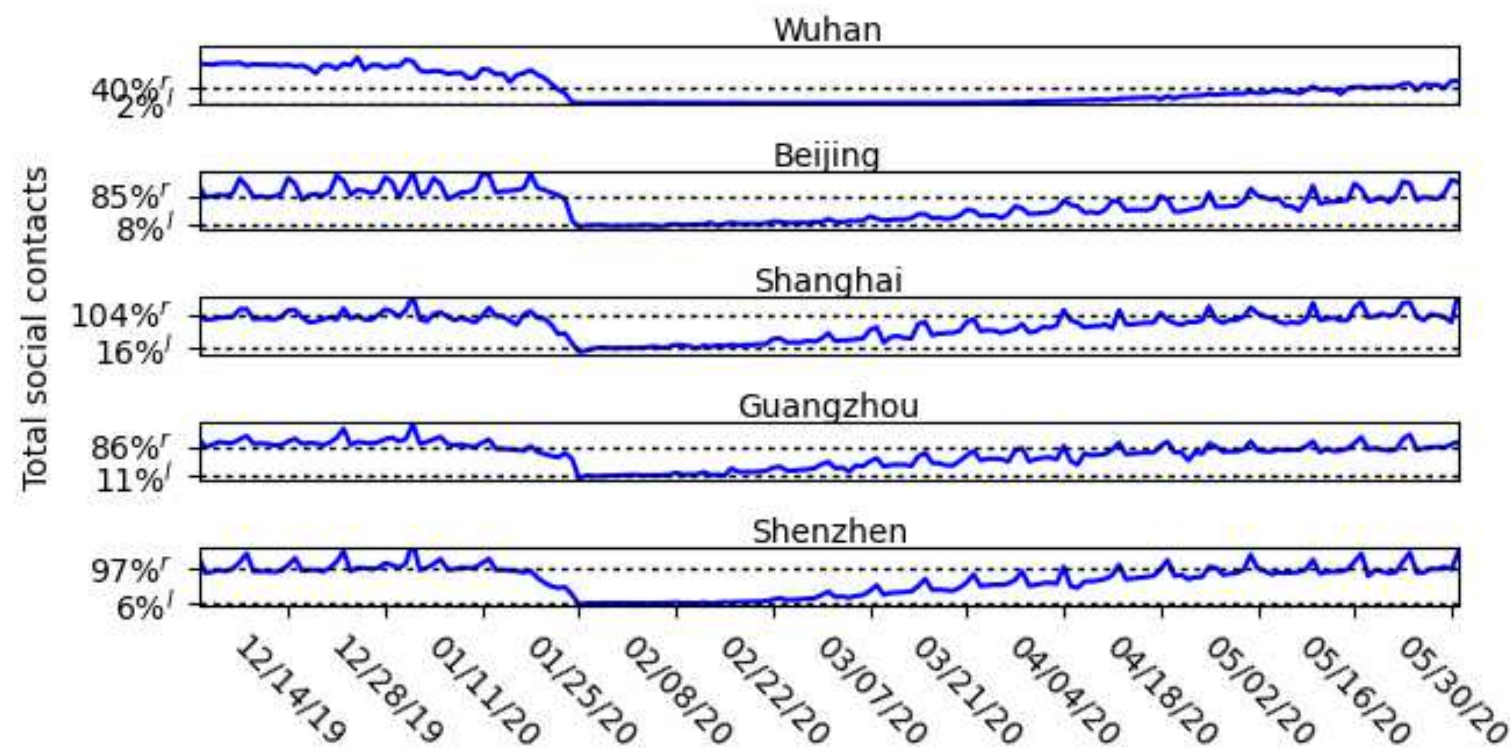

(D)

Fig. 1: Change in total social contacts index (TSCI) in Wuhan and four other major cities in China (Beijing, Shanghai, Guangzhou, and Shenzhen). (A) Change of TSCI in Wuhan from December 2019 through May 2020 in the form of a percentage of the average pre-lockdown level in December 2019 (100\%). (B) The enlarged view of (A) on the part of TSCI between $0 \%$ and $2 \%$. (C) The proportions of TSCI that occurred in different colored categories of places in December 2019. Different colors in (A) and (B) represent the same as those in (C). (D) The change of TSCI in the five cities. "r" denotes the pre-lockdown TSCI that the city restored to post-lockdown and "l" the pre-lockdown TSCI that the city decreased to during the lockdown. The two vertical lines 
163 in (A) denoting the lockdown and lockdown-lifting dates are only applicable to Wuhan as other 164 cities announced the two dates differently.

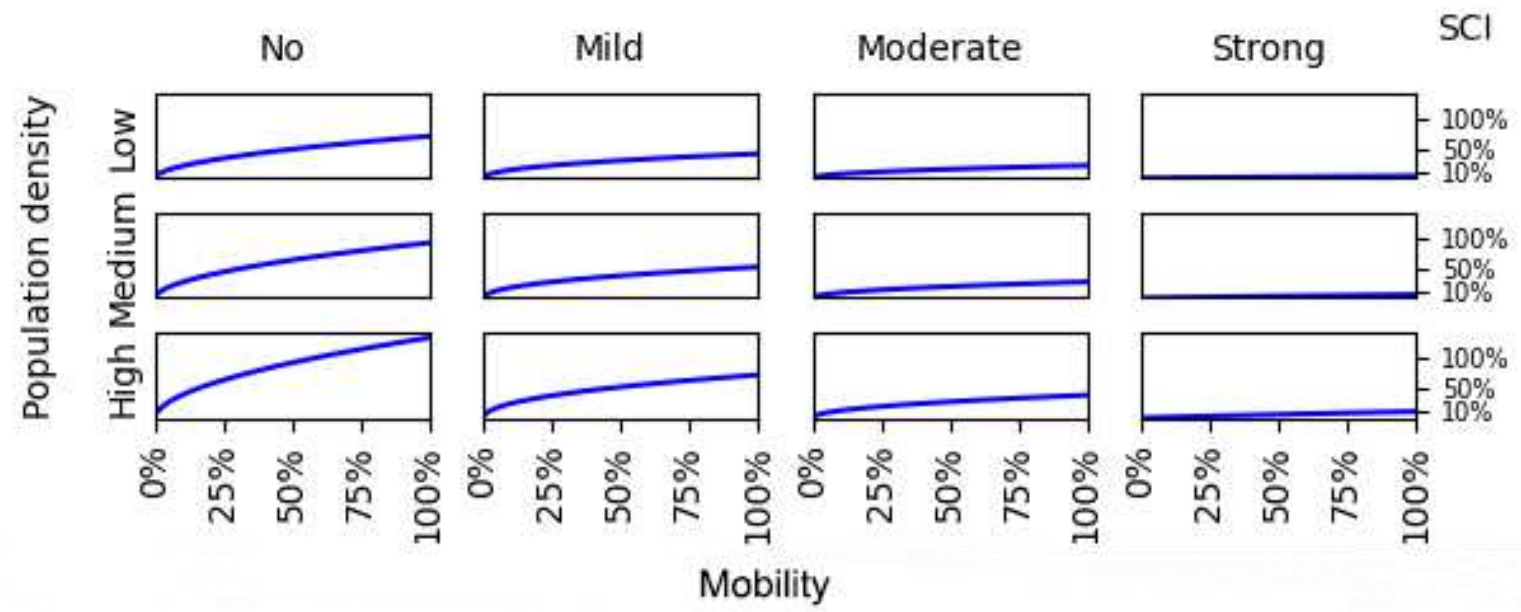

(A)

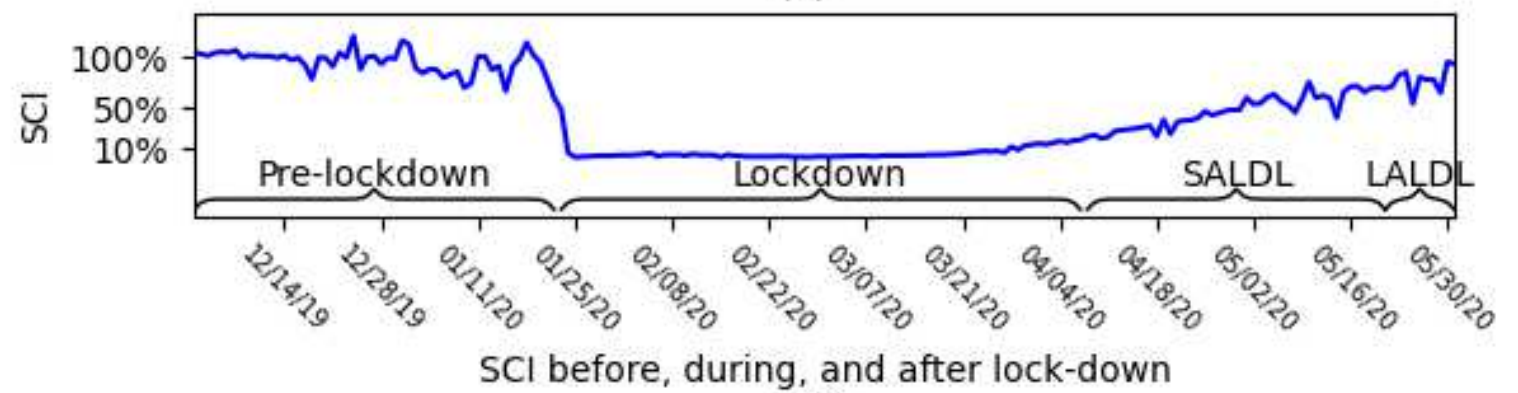

(B)

165

166

Fig. 2: Change in the mobility - social contact index (SCI) relationship in Wuhan under different levels of population density and physical distancing. (A) Each chart shows the changing trend of SCI (in the form a percentage of the averaged pre-lockdown SCI) over the mobility level increasing from $0 \%$ (no population movement), to $25 \%, 50 \%$, and finally $100 \%$ (no stay-at-home order) under a certain population density (low, medium, or high) for a specific intensity of physical distancing (none, mild, moderate, or strong). The four columns of charts from left to right are denoted with varying intensities of physical distancing imposed during different periods in Wuhan, i.e., prelockdown, LALDL, SALDL, and lockdown, respectively. (B) The daily change of SCI (in the form of a percentage of the averaged pre-lockdown SCI) in Wuhan from December 2019 through 
May 2020.

176

177

178

179

180

181

182

183

184

185

186

187

188

189

190

191

192

193

\section{Reconstruction of COVID-19 transmissions using a mobility and contact-based SEIR (MC- SEIR) model}

A classical SEIR model was modified to accommodate both intra-city and inter-city mobility and social contacts (forming a mobility and contact-based SEIR, MC-SEIR) to rebuild the transmission process of COVID-19 in Wuhan from December 2, 2019 through March 31, 2020. Because the social contact rate directly affects the transmission process, to more precisely assess the impact of physical distancing measures on transmission, a dynamic daily infection rate derived from SCI was leveraged to replace the fixed infection rate in the conventional SEIR model.

Specifically, the mobility and SCI data were utilized to estimate the instantaneous effective reproduction number $\left(R_{t}\right)$ via a generalized linear model. The transmission dynamic was calibrated using a Bayesian optimization method ${ }^{42}$ with the reported case data of Wuhan (see Methods sections "SEIR computation" and "Optimization of parameters for SEIR modeling" for more details). The model predicted daily new cases over the period from December 2019 through March 2020 with relatively high accuracy $\left(\mathrm{R}^{2}=0.95\right.$, Fig. 3), and the SCI explained 90\% (95 CI: 85\%94\%; $\mathrm{p}<0.0001$ ) of the variance in $R_{t}$ using the MC-SEIR model (Extended Data Fig. 4 A). If using only the mobility data instead of SCI, the correlation decreased to $80 \%$ (95\% CI: $71 \%-89 \%$; p<0.0001) (Extended Data Fig. 4 B). 
195
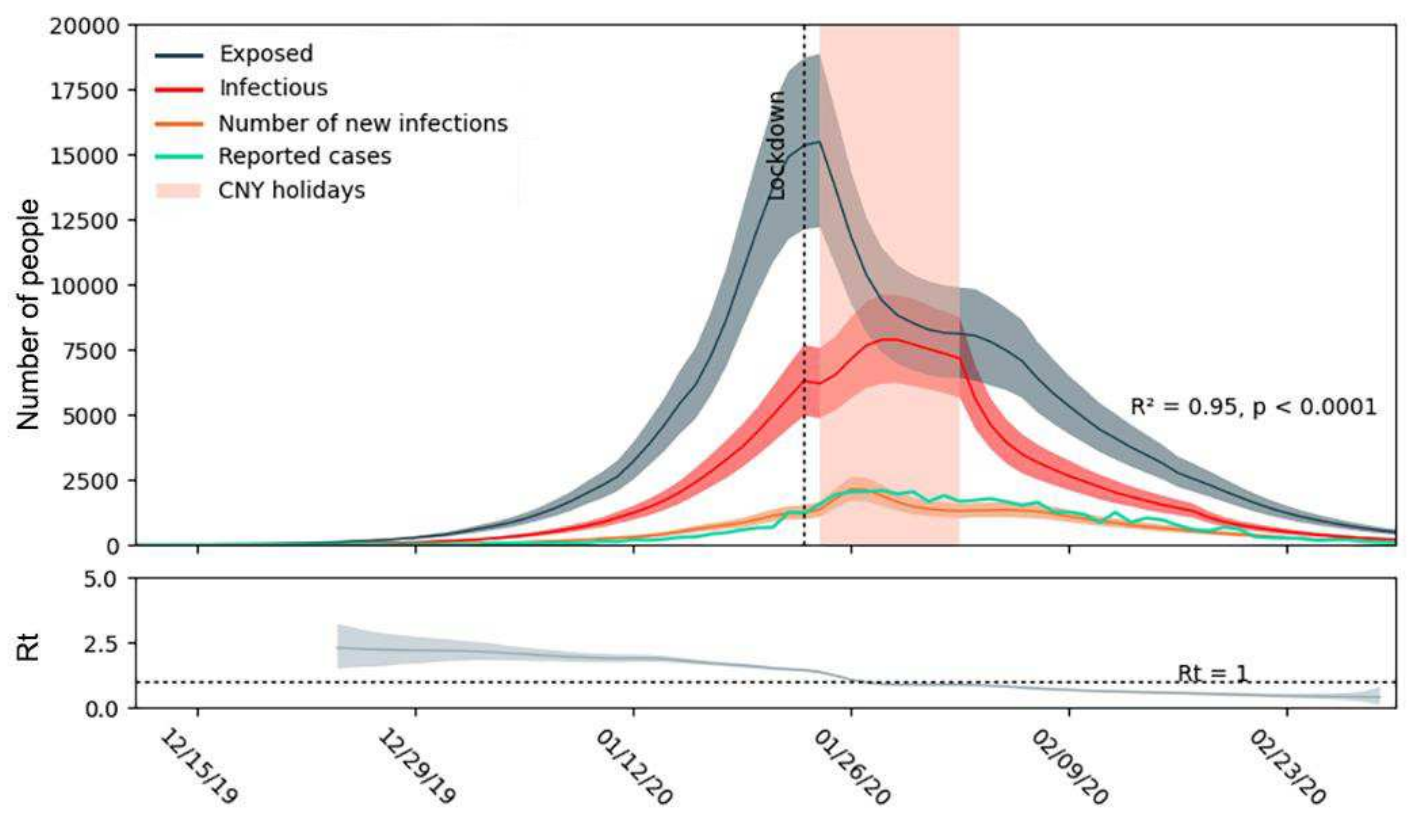

Fig. 3: Fitted curves and $R_{t}$ as predicted by the mobility and contact-based SEIR model. From top to bottom, the three curves in the upper chart represent the estimation of the daily exposed, infectious, and number of new infections from December 2019 through March 2020. The number of new infections examined against the daily reported cases yields the $\mathrm{R}^{2}$ of 0.95 at the statistical significance level of 0.0001 . The corresponding daily $R_{t}$ over the same period is displayed in the lower panel.

\section{Effect of physical distancing interventions on future resurgences without vaccination}

The effectiveness of interventions in preventing a COVID-19 resurgence was assessed by factoring in mobility, physical distancing, and population density under a no-vaccination scenario. The median duration required to contain a resurgence was estimated for each scenario, as shown in Fig. 4. Specifically, physical distancing measures were applied under a certain level of mobility and a selected population density scenario when the new cases exceeded 10 per day. The measures were lifted after no new cases were registered for 14 days. The scenarios and corresponding simulation results are expected to be useful in designing preventive interventions against COVID- 


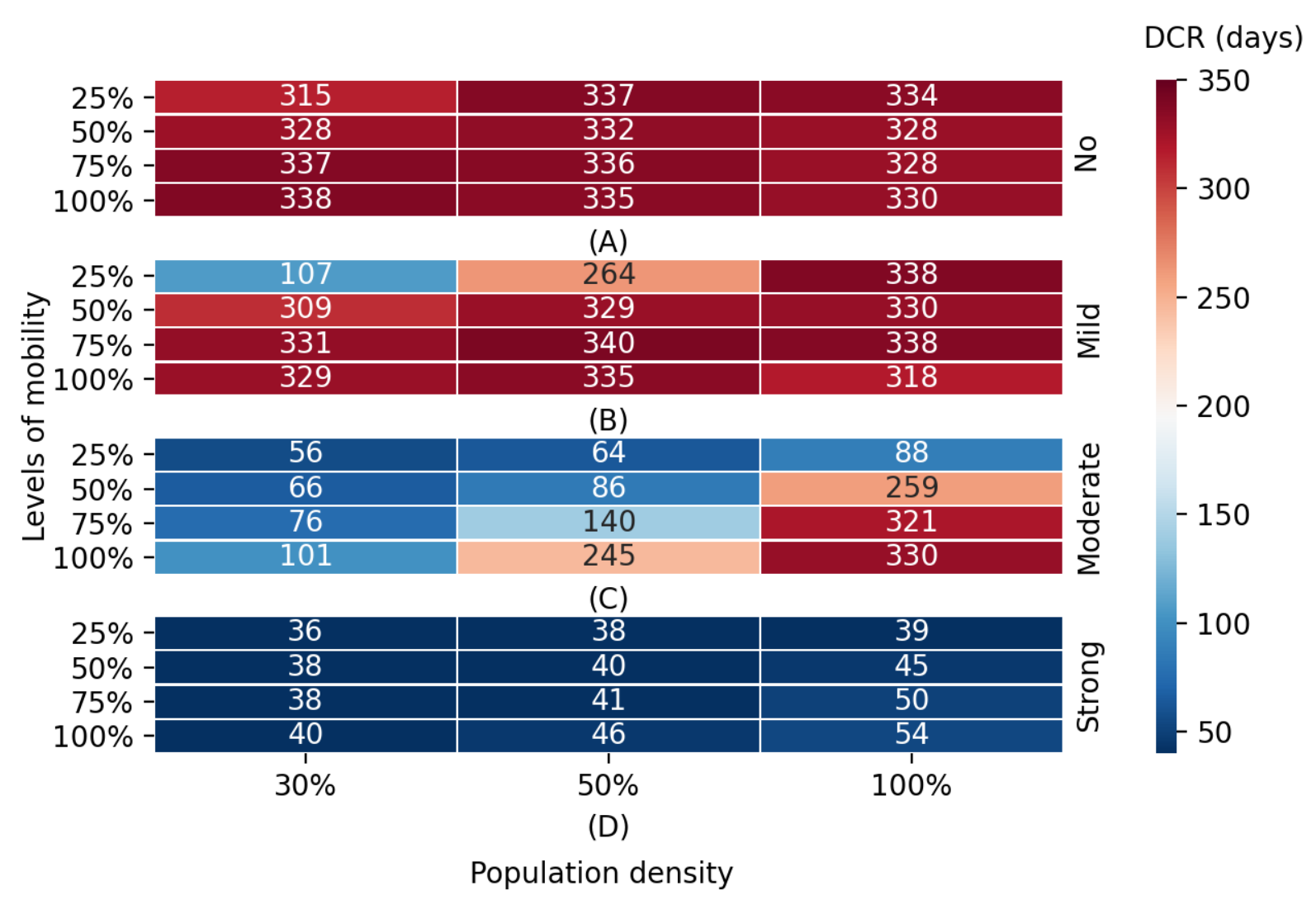

Fig. 4: Estimated effects of control measures on containing a resurgence of infections under 214 different population densities. (A)-(D) show for four intensities of physical distancing (i.e., none, 215 mild, moderate, and strong), respectively, the median duration required to contain a resurgence 216 (DCR, unit: days) in Wuhan with four levels of pre-lockdown mobility (25\%, 50\%, 75\%, and $217 \quad 100 \%$ ) under different population densities. The value in each cell denotes the DCR with respect 218 to its associated level of mobility, intensity of physical distancing, and population density. The population densities are $30 \%, 50 \%$, and $100 \%$, respectively, of that in Wuhan pre-lockdown. 
Physical distancing is deemed necessary for cities with a low (30\% of the pre-lockdown population density in Wuhan), medium (50\% of the pre-lockdown population density in Wuhan), or high (100\% of the pre-lockdown population density in Wuhan; 1282 people/km2) population density to curb resurgences of coronavirus infections (Fig. 4). Moderate and strong physical distancing measures could help a city with a low population density to relax interventions within three months if mobility reduction (e.g., reduced to $50 \%$ pre-lockdown level) was simultaneously applied. However, for a city with a high population density, a combination of mobility reduction and physical distancing measures would be needed to contain the resurgence within nine months. We found that the duration of intervention implementation [259 days; inter-quartile range (IQR): 162-345] for a city with high population density would almost triple that for a city with a population density of $50 \%$ or lower (86 days; IQR: $71-104)$ if both moderate physical distancing

\section{Joint effects of vaccination and physical distancing in avoiding resurgences}

Vaccines against SARS-CoV-2 may become available as early as late 2020 or early 2021, and it is imperative to assess the potential combined effects of vaccination and physical distancing, especially there will be a period when only limited supplies of vaccines are available or only a limited proportion of people (lower than the theoretical herd immunity threshold) are vaccinated. Thus, we designed a set of scenarios where physical distancing measures were leveraged to end the epidemic for a city with an increasing proportion of vaccinated population. In total, $64.2 \%$ of the population (i.e., herd immunity threshold derived from the median of a set of reported $\mathrm{R}_{0}$ values $^{43}$ ) would be vaccinated within one year. The effectiveness of vaccines (the seroprotection rate) was set as 75\% (neutral scenario) (see Methods section "Simulation of the joint effects of vaccination and physical distancing" for more details). According to the simulation results (Table 1), the combination of physical distancing and vaccination was predicted to further reduce the 
number of infected cases compared with vaccination alone. The reduction effects were predicted to be more significant for cities with a high population density, such as Wuhan. Specifically, $97.72 \%, 99.99 \%$, and $99.99 \%$ of the infections were predicted to be avoided under mild, moderate, and strong physical distancing intensities, respectively. Strong and moderate physical distancing together with vaccination were predicted to suppress the infections to low levels, i.e., 213 (95\% CI: 122-347) and 1800 (95\% CI: 991-2821) cases in one year, respectively, and thus were recommended to be adopted. Meanwhile, the total duration of physical distancing to end the resurgences decreased gradually from 350 days (95\% CI: 338-354; mild) to 234 days (95\% CI: 166-395; moderate) and then 43 days (95\% CI: 33-64; strong). The results implied that strong but short physical distancing would be a better solution for curtailing resurgences in terms of the case number and intervention duration.

Compared with the no-vaccination scenario, vaccination combined with physical distancing was predicted to contain the resurgence without relying on mobility reduction, whereas a gradual vaccination process alone could not achieve this. Specifically, for cities with low population density, physical distancing would no longer be required. For cities with medium population density, vaccination could shorten the duration of physical distancing measures required to end the resurgence by $36 \%-78 \%$ and limit the number of infected cases to 298 (95\% respectively. For cities with high population density, vaccination enabled strong physical distancing to be replaced by moderate physical distancing. Consequently, it is of value to apply joint physical distancing and vaccination interventions while approaching herd immunity, especially in large cities with high population densities, such as Wuhan.

To evaluate uncertainties, the above simulations were replicated under pessimistic and optimistic scenarios with effectiveness set as $50 \%$ and $100 \%$, respectively. Without loss of generality, the population density was set as the $100 \%$ pre-lockdown population density of Wuhan for the optimistic, neutral, and pessimistic scenarios. The results showed that the uncertainty (IQR of daily new cases) would be high when applying limited physical distancing measures. In the 
pessimistic scenario, the peak of daily new infections was 1.25 to 8.08 times that in the neutral scenario when only no or mild physical distancing measures were applied, whereas the peak of daily new cases was similar (1.08 and 0.97 times) when moderate or strong physical distancing was imposed (Fig. 5). This further confirmed that the joint implementation of physical distancing and vaccination can reduce the uncertainty in ending the epidemic.

To test the generalizability of our proposed SCI models under varying population densities, six cities in China (low-density: Zhuzhou and Qiqihar; medium-density: Hefei and Hangzhou; and high-density: Beijing and Chengdu) were examined with each density set forming a group under one population density scenario. The four sets of physical distancing measures (e.g., "the closure of schools and $20 \%$ reduction in contact in all other categories" for mild intensity) were directly applied to these cities, but an SCI-mobility curve was derived for each city (see Methods section "Validation of the joint vaccination and physical distancing interventions in other cities" for more details). According to the results (Extended Data Table 4), all of the low-density scenarios required no physical distancing when vaccination was applied. The medium-density cities (Hefei and Hangzhou) had lower than 1500 cases in one year even with mild physical distancing. Thus, we could further infer that the mild, moderate, and strong physical distancing measures would all be acceptable for medium-density cities according to the number of potential cases in one year. This result is similar to what was confirmed in the $50 \%$ population density scenario in Wuhan (Extended Data Table 4). In all three high-density scenarios, the no and mild physical distancing measures failed to stop the resurgence and reduce the high number of infections. Thus, the moderate and strong physical distancing measures would be acceptable for high-density cities when vaccines became available. Strong physical distancing measures should be applied first because this intensity would likely end the need for interventions within two months. The results in all six cities showed similar results to those in the corresponding population density scenarios in Wuhan. This evidence suggests that our proposed mobility-SCI model and the explicit sets of physical distancing measures could be used to inform the combined effects of interventions in other cities with similar population densities. 
301 Table 1. Simulated joint effects of vaccination and physical distancing measures

\begin{tabular}{|c|c|c|c|c|}
\hline $\begin{array}{l}\text { Population } \\
\text { density }\end{array}$ & $\begin{array}{l}\text { Physical } \\
\text { distancing }\end{array}$ & $\begin{array}{l}\text { Infected cases in one year } \\
\qquad(95 \% \mathrm{CI})\end{array}$ & $\begin{array}{c}\text { Reduction } \\
\text { rate of } \\
\text { cases }^{\mathrm{a}}\end{array}$ & $\begin{array}{l}\text { Duration under } \\
\text { physical distancing }\end{array}$ \\
\hline \multirow{4}{*}{$\begin{array}{c}30 \% \\
\text { population } \\
\text { density of } \\
\text { Wuhan }\end{array}$} & No & $47(9-189)$ & - & - \\
\hline & Mild & $54(11-196)$ & - & $0(0-0)$ \\
\hline & Moderate & $49(11-194)$ & - & $0(0-0)$ \\
\hline & Strong & $59(16-218)$ & - & $0(0-0)$ \\
\hline \multirow{4}{*}{$\begin{array}{c}50 \% \\
\text { population } \\
\text { density of } \\
\text { Wuhan }\end{array}$} & No & $6894(1302-11565)$ & - & - \\
\hline & Mild & $776(368-1064)$ & $88.74 \%$ & $163(90-242)$ \\
\hline & Moderate & $298(130-438)$ & $95.68 \%$ & $55(35-80)$ \\
\hline & Strong & $205(94-347)$ & $97.02 \%$ & $29(0-45)$ \\
\hline \multirow{4}{*}{$\begin{array}{c}100 \% \\
\text { population } \\
\text { density of } \\
\text { Wuhan }\end{array}$} & No & $17.72 \%(16.26 \%-18.74 \%)^{b}$ & - & - \\
\hline & Mild & $0.40 \%(0.22 \%-0.60 \%)^{b}$ & $97.72 \%$ & $350(338-354)$ \\
\hline & Moderate & $1800(991-2821)$ & $99.99 \%$ & $234(166-295)$ \\
\hline & Strong & $213(122-347)$ & $99.99 \%$ & $43(33-64)$ \\
\hline
\end{tabular}

a The reduction rate of cases refers to the percentage of cases that could be reduced if a physical distancing intensity (listed on the left) were applied compared with a no physical distancing scenario. The no physical distancing scenario and the scenarios with a very limited number of cases that do not require physical distancing are marked as "-."

$\mathrm{b}$ The number of cases is presented in the form of a percentage of potentially exposed population (approximately 102.25 million in Wuhan) if the number is so large; see Methods "Estimation of population migration and associated population density variations" for more details. 

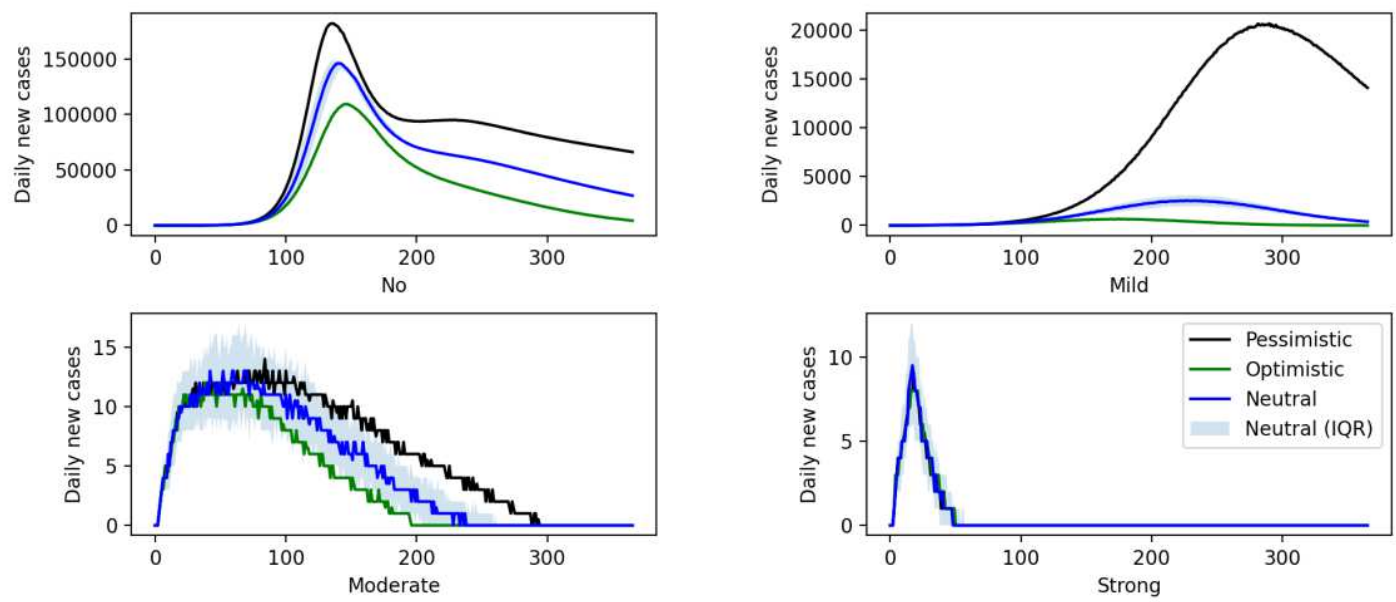

Fig. 5: Joint effects of vaccination and physical distancing under optimistic, pessimistic, and neutral scenarios. The daily new case curves are plotted under the vaccination and physical distancing intensities. The $x$-axis represents the daily new cases and the $y$-axis represents the number of days since the start of the simulation. For the neutral scenario, the $25 \%$ and $75 \%$ quantiles of the daily cases are also displayed.

\section{Discussion}

Our study assessed the effects of physical distancing interventions on the resurgence of COVID-19 with increased mobility and social contacts following the lifting of lockdown measures under both vaccination and no-vaccination scenarios. The effectiveness and duration of physical distancing interventions in containing future resurgences highly depends on the intensity of measures, population density, and availability of vaccines. Large cities with a high population density, such as Wuhan $(1282 / \mathrm{km} 2)$, are more vulnerable to resurgence when reopening the economy and society. On the one hand, the naturally high SCI in these cities would require more effort (longer and stronger physical distancing and stronger mobility reduction) than that necessary for less dense cities. On the other hand, containing a resurgence in the absence of an effective vaccine is a costly process. For cities with high population density, such interventions may result in the closure of $80 \%$ of shops (strong physical distancing) for another two months. Thus, it is important to take precautionary measures against future resurgences in the upcoming several 
months before effective vaccines become available. Socioeconomic activities can be safe if the vaccinated population reaches the herd immunity threshold $(64.2 \%)$ as derived from the $\mathrm{R}_{0}$ value (2.79). When there are imported cases, high-density cities would still require moderate or stronger physical distancing, whereas low-density cities could curtail the transmission solely by vaccination.

Effective vaccination with a high coverage in population can greatly ease the reliance on physical distancing interventions in terms of their implementation intensity and duration. Specifically, stay-at-home orders (mobility and contact reductions used in our simulation) would

Although this study showed that non-pharmaceutical interventions are likely to substantially reduce COVID-19 transmission, it is difficult for the public to adhere to travel and physical distancing measures for a long period ${ }^{5,24,43,44}$, and subsequent waves of resurgence may emerge after relaxing interventions and resuming normal levels and patterns of travel ${ }^{5}$ before achieving herd immunity through vaccination. This paper provides a framework and set of outputs that can be used across a wide range of settings, including (i) more precise estimates of COVID19 outbreaks and the efficacy of interventions under both vaccination and no-vaccination scenarios; (ii) identification of the most effective combinations of physical distancing and vaccination interventions and their intensities for preventing or suppressing resurgences; and (iii) supporting 
disease control strategy design through improved understanding of interventions and their effects across space and time in regions with different population densities.

Our findings should be considered in the context of several assumptions and data limitations. First, we did not derive individual-level mobility and social contacts to estimate COVID-19 transmission owing to data availability and privacy issues. If demographic attributes of individuals are available in the future ${ }^{35}$, then we could extend the methodology and analyses to detect potential social disparities in the vulnerability to COVID-19 and assess potential heterogeneities in the efficacy of intervention. Second, the mobile phone-derived data used for parameterizing travel and physical distancing interventions in our model may not be representative of populations in other countries owing to variations in coverage and population dynamics. However, the data used here cover over $70 \%$ of the population within China ${ }^{11}$, and thus represent the Chinese population reasonably well. Third, the accuracy of our model relies on the accuracy of the epidemiological parameters derived from the reported case data, the quality of which might be constrained by case definitions, the capacity for diagnosis and surveillance, and other factors varying across countries, regions, and time ${ }^{45}$. Fourth, other factors and interventions, such as hand washing and wearing facemasks, may also contribute to mitigating COVID-19 spread across space and time ${ }^{46,47}$, but our simulations did not specify their contributions to transmission. Our methods integrate near-real time mobility and social contact data, thereby suggesting that our approaches can be adapted to address emergent needs given the rapid changes in the COVID-19 transmission dynamics post-lockdown.

\section{Materials and Methods}

\section{Case incidence data}

The daily numbers of COVID-19 cases by date of illness onset in Wuhan as of April 17, 2020, as obtained from the national information reporting system for notifiable infectious diseases in China, were used to further evaluate the performance of the baseline model. There was an abnormal increase in the number of cases in Wuhan on February 1, 2020, based on the date of 
illness onset. We interpolated the number on February 1 as the mean number of cases reported on January 31 and February 2 in the epicurve.

\section{Estimation of population migration and associated population density variations}

Population migration played an important role in our assessment of the population in the study area (i.e., Wuhan) and subsequently significantly impacted the transmission dynamics. Tencent's mobile device dataset. For a given day $(t)$, the relative values of the population inflow $\left(I_{r, t}\right)$ and outflow $\left(O_{r, t}\right)$ were calculated by detecting the number of move-in and move-out mobile devices. These values were used to estimate the actual inflow $\left(I_{t}\right)$ and outflow $\left(O_{t}\right)$ together with the relative value of the population $\left(U_{t}\right)$ (number of mobile device users after deduplication) and the dynamic population $\left(P_{t}\right)$ on day $t$. Finally, the $P_{t}$ was updated based on the estimated inflow and outflow on that day, as follows:

$$
\begin{aligned}
I_{t} & =I_{r, t} * \frac{P_{t}}{U_{t}} \\
O_{t} & =O_{r, t} * \frac{P_{t}}{U_{t}} \\
P_{t+1} & =P_{t}+I_{t}-O_{t}
\end{aligned}
$$

The population density of a city is influenced by population migration, so it varies over time. Population density may directly affect the base contact rate between individuals. In our simulations, the $P_{t}$ of Wuhan at the beginning of the study period was obtained from the government statistical data [i.e., 11.21 million (Wuhan's permanent population); December 1, $2019]^{48}$ and updated on a daily basis using the migration data. Consequently, the population density also changed daily during the study period, but it was assumed to be homogeneous within the city.

In addition, the cases that were registered in the city, regardless of being members of permanent population or members of migration population, would be included in the total number of cases in a simulation scenario. Thus, to better evaluate the risk of COVID-19 to the population under this statistical caliber ${ }^{34}$, we used an equivalent population base named as "potentially 
exposed population", which was calculated by summing the city's permanent population and its annualized inflow population.

$$
\begin{gathered}
\operatorname{TSCI}_{t}=\sum G_{i, t, k}\left(G_{i, t, k}-1\right) \\
G_{i, t, k}=\frac{U_{i, t, k}}{C}
\end{gathered}
$$

where $G_{i, t, k}$ denotes the ambient population in bin (i, t, k), $U_{i, t, k}$ the number of mobile device users in the same bin, and $C$ the conversion ratio, which is a constant.

On a per-person level, the SCI on day t can subsequently be calculated (Extended Data Fig. 2) as follows:

$$
S C I_{t}=\frac{T S C I_{t}}{P_{t}}
$$


where $P_{t}$ is the total dynamic population of the study area on day $t$.

The SCI computed using mobile geolocation data can help one to understand the transmission process with a higher spatiotemporal resolution by providing the number of potential social contacts on a per-person basis. To explore the non-linear relationship between SCI and mobility, $10 \%$ to $100 \%$ (incremented by $10 \%$ ) of mobile device users were randomly selected, and their corresponding contact events were detected in the form of spatiotemporal co-presence (Extended Data Fig. 1). Thus, a series of mobility-SCI pairs was formed, based on which an empirical relationship was built to estimate SCI values in scenario-based simulations, given an assumed restoration or reduction in mobility levels.

Quantifying the relationship between mobility and social contacts

To quantify the association between mobility and the SCI, we used an allometric curve ${ }^{29}$, as follows:

$$
S C I_{t}=\alpha \times\left(h \times P_{t} / A\right)^{\beta}
$$

where $P_{t}$ denotes the dynamic population (both at home and outside the home) on day $t$, $A$ is the size of the study area, and $P_{t} / A$ is the population density. $h$ denotes a ratio for quantifying the mobility level of the entire population (i.e., $P_{t}$ ), which can also reflect the level of mobility reduction/restoration. For instance, a stay-at-home order followed by approximately $50 \%$ of the population can be simulated by setting $h$ as 0.5 . Thus, the mobility is calculated as $h \times P_{t}$ and the mobility per unit area is calculated as $h \times P_{t} / A$. $\alpha$ and $\beta$ together define a power law equation representing the influence of physical distancing measures. Higher values of $\alpha$ and $\beta$ indicate weaker physical distancing, thereby implying more social contact under a given population density and mobility level. In addition, an inflow of population can cause an increase in $P_{t}$ and an increase in population density and $S C I_{t}$.

To fit this model, the social contact data of Wuhan for one week during the pre-lockdown period (December 1 to December 7, 2019) were extracted and used to generate a set of mobilitySCI observations. The social contacts were categorized into five types according to the places 
where they occurred, namely the residential community $\left(C_{r}\right)$, work $\left(C_{w}\right)$, school $\left(C_{s c h}\right)$, shopping/recreation $\left(C_{s}\right)$, and others $\left(C_{o}\right)$.

$$
T S C I=C_{r}+C_{w}+C_{s c h}+C_{s}+C_{o}
$$

The values of each of these types of contact under a given mobility level (from $1 \%$ to $100 \%$ ) were also recorded and denoted as $C_{k, i}$, where $k \in\{r, w, s c h, s, o\}$ and $i \in\{1 \%, 2 \%, 3 \%$, $\ldots, 100 \%$ \}. The mobility level was obtained by randomly sampling the overall mobile device users (represented by $i$ ) and calculating the contact events belonging to the given category $k$. The contact value $\left(S C I_{t, i}\right)$ with respect to a given mobility level $i$ and a physical distancing intervention was then derived (Extended Data Fig. 2), where $p_{k, i}$, denoting a ratio between 0 and 1 , was used to quantify the contacts of a given category $k$ under the mobility level $i$ on day $t$, as follows:

$$
S C I_{t, i}=\left(\sum p_{k, i} \times C_{k, i, t}\right) / P_{t}
$$

A set of $S C I_{t, i}$ and $i$ values were generated under a given physical distancing intervention specified by $\alpha$ and $\beta$ and a population density $\left(P_{t} / \mathrm{A}\right)$. These observations were used to quantify the relationship between a specified mobility level and an SCI value for a given population density. Therefore, the $\alpha$ and $\beta$ values for a given physical distancing intervention could be obtained as follows:

$$
S C I_{t, i}=\alpha \times\left(i \times h \times P_{t} / \mathrm{A}\right)^{\beta}
$$

The above process was conducted four times to determine the parameters $\alpha$ and $\beta$ under varying intensities of physical distancing interventions, namely none, mild, moderate, and strong. Using the mobility data of Wuhan from December 2019 through May 2020, we were able to derive the social contact rates at different places and infer the opening and closure of different places during the periods in which physical distancing interventions of varying intensities were implemented. As shown in Extended Data Table 1, the four intensities were consistent with those imposed in the following periods: pre-lockdown, LALDL, SALDL, and lockdown. Each set of measures was as follows. No physical distancing refers to the normal status pre-lockdown; mild 
physical distancing includes the closure of schools and a $20 \%$ reduction in contact in all other categories; moderate physical distancing includes the closure of schools, an $80 \%$ reduction in contact in shopping/recreation, and a 50\% reduction in contact in all other categories; and strong physical distancing includes only $50 \%$ of the pre-lockdown-level contact in residential communities and the closure of all other non-essential facilities.

The above considerations indicate that the four intensities of physical distancing can be implemented explicitly because each intensity is linked to a set of control measures (e.g., closure of schools and $20 \%$ closure of other services), which can then inform the changes in the SCI. These changes then indicate the potential variations in disease transmission.

To validate the proposed mobility-SCI relationships under the four intensities of physical distancing or the four sets of explicit physical distancing measures (Fig. 2), the relationships were examined against the observed mobility-SCI values in Wuhan over the corresponding periods of pre-lockdown, LALDL, SALDL, and lockdown under the same population density (low, medium, or high). The low population density was set to approximately $30 \%$ of the population of Wuhan, medium population density to $50 \%$ of the population, and high population density to $100 \%$ of the population. Under each physical distancing intensity, the modeled mobility-SCI relationships for the three population densities followed the same allometric function ${ }^{37}$. Thus, only four relationships required validation (Extended Data Fig. 3).

The results indicated that the modeled SCI values under each mobility level (10\% to $100 \%$ with increments of $10 \%$ ), that is, for each relationship, were significantly correlated with the observed SCI values (Pearson correlation coefficients ranging from 0.95 to 0.97 for all of the relationships, each with $p<0.0001$; mean absolute error ranging from 0.03 to 1.42 ). Therefore, the proposed mobility-SCI metric was considered useful for measuring the actual intensities of physical distancing that existed over the aforementioned periods for different population densities. Accordingly, this metric was used to quantify the intensities of physical distancing in our simulations. 
For the purpose of this computation, the population $(N)$ was subdivided into five groups, namely susceptible $(S)$, exposed $(E)$, infectious $(I)$, recovered/removed $(R)$, and vaccinated $(V)$. During each time step, five sub-steps were performed sequentially, as follows:

$$
\begin{gathered}
N=S+E+I+R+V \\
\frac{d S}{d t}=S-E_{I} \frac{S I}{N}+\xi_{R} R+\xi_{V} V \\
\frac{d E}{d t}=E_{I} \frac{S I}{N}-E_{C} \\
\frac{d I}{d t}=E_{c}-r_{t} I \\
\frac{d R}{d t}=r_{t} I-\xi_{R} R \\
\frac{d V}{d t}=V_{e, t}-\xi_{V} V
\end{gathered}
$$

First, the disease transmission coefficient $E_{I}$ was calculated based on a transmission process following a Poisson $\left(\lambda=R_{S}\right)$ distribution ${ }^{50}$. The theoretical number of newly exposed people $E_{I} * I$ was then multiplied by the percentage of susceptible people $(S / N)$ in the city. Here, the SCI-adjusted transmission rate $\left(R_{S}\right)$ was obtained from the basic reproduction rate $\left(R_{0}\right)(2.2$; 95\% CI: 1.4-3.9), divided by the average number of days $\left(t_{g}\right)(5.8 ; 95 \% \mathrm{CI}: 4.3-7.5)$ between the onset and first medical visit and isolation, and weighted using the level of social contact $\left(S_{c}\right)$ determined using the mobility data. $S_{C}$ was computed using a generalized linear model consisting of the parameters $\beta_{0}, \beta_{1}$, and $\beta_{2}$. The observed SCI values were derived from the TSCI divided by the total dynamic population of the city when fitting the models. In the simulation processes, the SCI values were derived using our proposed physical distancing and mobility reduction measures. We assumed that the mean incubation period for exposed people was 4 days (IQR: 2-7 days) ${ }^{1}$. A set of onset dates (i.e., current time point plus a stochastic incubation period) was stochastically generated and recorded together with the onset dates of the previous exposed population, as follows:

$$
R_{S}=S_{c} * R_{0} / t_{g}
$$




$$
S_{c}=\beta_{0} * S C I^{\beta_{1}}+\beta_{2}
$$

Second, the exposed people were considered infectious if their onset dates (specified in the previous sub-step) were equal to the current time step (i.e., day $t$ ). The number of such people is denoted by $E_{c}$. Typically, a direct estimation based on the total number of existing exposed people and the conversion rate $(\sigma)$ derived from the delay in symptom onset distribution were applied.

For instance, $20 \%$ of the exposed population on day $t-1$ would be converted to the infected population if $\sigma$ is equal to 0.2 . However, such an approach can cause a premature conversion of the exposed population to the infectious population, e.g., the abrupt peak in mass social contact before the Chinese New Year holidays might have resulted in an immediate increase in the exposed population but a delayed increase in the infectious population. In contrast, a zero-delay peak of new infectious people would appear on the next day if only the number of people exposed in the current timestep were considered instead of their potential onset days.

Third, the infected people were later removed/recovered at an average rate of $r_{t}$, where $t \in\{1,2,3,4,5\}$, which represents the five periods identified in Wuhan ${ }^{51}$. A dynamic $r_{t}$ was applied in light of the significant changes in the diagnosis and isolation strategies implemented during December 2019 to March 2020. $r_{t}$ was modeled as an optimizable parameter and was determined using a Bayesian optimization method ${ }^{42}$. Everyone in the recovered/removed group lost immunity at a rate of $\xi_{R}$ every day during the period.

Fourth, when fitting against the real situation in Wuhan, the initial model did not include the vaccination group and vaccination process (the vaccinated population was 0 ). However, they were included in the SEIR model in simulating the combined effects of vaccination and physical distancing. On day $t$, part of the vaccinated population $\left(V_{e, t}\right)$ was immunized, and everyone in the vaccinated group lost immunity at a rate of $\xi_{V}$ every day.

Finally, the exported and imported population were processed to update the total population in the city using the population migration data. The exported population followed the same fractions of the susceptible, exposed, infectious, and recovery/removed population in the current timestep in the city, while the imported population was considered to join the susceptible 
population.

Optimization of parameters for SEIR modeling

We developed the MC-SEIR model by modifying the classical SEIR model with mobility and social contact data to reconstruct the transmission dynamics of COVID-19 in Wuhan between December 2019 and March 2020. The model was calibrated within a Bayesian optimization framework by using a tree-structured Parzen estimator (TPE) ${ }^{42}$, in which the relationship between social contact and infection rate as specified by the generalized linear model, the removal rate $r_{t}$, and the initial cases were optimizable. These parameters were estimated by minimizing the squared error between the model-estimated daily new cases and the actual case report data. To deal with the uncertainty in the stochastic SEIR model, each parameter set was evaluated 150 times. The mean squared errors were finally used as the object function values by the TPE.

We also built a linear model between the SCI (4 days ahead) and effective reproduction number $R_{t}$ by using the case report data of Wuhan for the period of December 1, 2019 through March 31, 2020. A 4-day (median value of the incubation period) time lag was applied to examine the lagged correlation between $R_{t}$ and SCI. According to the results, SCI explained $90 \%$ of the variance in $R_{t}$ estimated using MC-SEIR (Extended Data Fig. $4 \mathrm{~A}$ ), which improved over that using only the mobility data by 10\% (Extended Data Fig. 4 B).

\section{Simulation for containing resurgences through physical distancing without vaccination}

The resurgence of COVID-19 is highly possible, and there is a high risk of resurgence in the near future. Therefore, it is imperative to devise appropriate physical distancing interventions that can help to effectively contain potential resurgences. We simulated resurgence under different intervention strategies and levels of mobility and evaluated the effectiveness of the strategies using the median duration required to contain the resurgence. A physical distancing intervention was commenced under a certain level of mobility when the number of daily new cases exceeded a threshold (i.e., 10 people in the simulation). Thus, the SCI could be controlled under the proposed 
intervention, along with the level of mobility, to decelerate the transmission process. The SCI value was acquired from the SCI curve defined earlier with respect to the level of mobility, intensity of physical distancing, and population density. Ideally, the number of new cases would decrease owing to significant reductions in the TSCI and SCI. The interventions were lifted when there were no new cases for 14 consecutive days. Otherwise, the measures were continuously implemented for 1 year (the remainder of the total simulation period). In other words, an estimated duration of more than 300 days indicated that the conducted interventions could not contain the resurgence effectively.

\section{$\underline{\text { Simulation of the joint effects of vaccination and physical distancing }}$}

To understand the joint effects of vaccination and physical distancing in the cities with varying population densities, a set of scenarios differentiated by vaccination, physical distancing, and population density were designed. During the simulation period (i.e., 365 days), the same number of people would be vaccinated every day (approximately $0.18 \%$ of the total population). By the end of the simulation period, $64.2 \%$ of the population would be vaccinated. The proportion of the vaccinated population $\left(1-1 / \mathrm{R}_{0}\right)$ was derived from $\mathrm{R}_{0}(2.79)$, i.e., the median $\mathrm{R}_{0}$ value as reported in a set of previous studies ${ }^{52}$ (Extended Data Table 2).

The vaccinated population was assumed to be vaccinated twice (on day 0 and day 14), and gradually obtained immunity to SARS-Cov-2. Specifically, seven types of COVID-19 vaccines that had finished phase II trials (Extended Data Table 3) were reviewed. The probability of inducing an immune response (probability of seroconversion) was recorded on different observation days (e.g., 75\%; day 14). These records were later grouped by date and used to calculate the quantiles (i.e., $25 \%, 50 \%$, and $75 \%$ ) of seroconversion on each date (e.g., 14, 28, or 42 days since the first shot) (Extended Data Fig. 5). In our simulations, the median value of seroconversion was used. Under pessimistic, neutral, and optimistic scenarios, 50\%, 75\%, and 100\% of the population that had experienced seroconversion would acquire immunity, respectively. The population with immunity could not infect or be infected by other people. 

either recovery from infection or vaccination, but the achieved immunity will fade at different speeds. For the recovered group, we assumed that their immunity would follow a similar decreasing curve such as that for severe acute respiratory syndrome (SARS), which is also caused by coronavirus, because there was no available systematic review or report on the immunity fading population would lose their immunity to COVID-19 in the first year after their recovery ${ }^{53}$. For the vaccinated group, we assumed that their immunity would fade at a higher speed. Thus, a unique fading curve was adopted to simulate the immunity fading of the vaccinated population. However, there were also no data on the long-term effects of COVID-19 vaccines as well as other coronaviruses (e.g., SARS and Middle East respiratory syndrome-related coronavirus). Therefore, the fading trend of influenza vaccination was used instead. We assumed that $53.05 \%$ (95\% CI: $45.79 \%-60.29 \%)^{54}$ of the vaccinated population would lose their immunity in the first year.

Simultaneously, physical distancing measures (with mild, moderate, or strong intensity) would commence when daily new cases exceeded a threshold (i.e., 10), which would later be lifted if there were 14 consecutive days with no new cases. It was considered that vaccination and mobility reduction could achieve a similar effect, that is, exposure reduction in population that may potentially cause infection. However, compared with vaccination measures, travel restrictions have serious adverse socioeconomic effects. Moreover, travel restrictions may be difficult to enforce in some countries. Therefore, the physical distance measures that we adopted excluded mobility reduction in this scenario; that is, the mobility was $100 \%$ in the simulations.

The scenarios were simulated under three population densities [i.e., 30\% (low), 50\% (medium), and 100\% (high) of the population density of Wuhan] and four physical distancing intensities. Each of the 12 scenarios was run 200 times to evaluate the uncertainty. In the simulations, contacts caused by people belonging to the vaccinated and removed/recovered groups were removed from the TSCI because they could not infect or be infected by other people. 
Finally, the cumulated infected population and physical distancing durations were reported $630 \quad$ with $95 \%$ CIs in Table 1.

634 we replicated the simulations of the combined effects of vaccination and physical distancing 635 measures in six other cities, namely Zhuzhou and Qiqihar (low density), Hefei and Hangzhou 636 (medium density), and Beijing and Chengdu (high density), and compared them with Wuhan's 637 population density scenarios. For each city, the mobility-SCI relationships were first extracted 638 under no, mild, moderate, and strong physical distancing intensities. In this process, the set of 639 measures under a physical distancing intensity in Wuhan remained unchanged to examine if the 640 measures can be feasibly applied to a city with a similar population density. The extracted SCI 641 curves were later used to derive the SCI value of a given city under various physical distancing 642 and vaccination scenarios. The simulations, which were the same as those for Wuhan, were then 643 replicated, in which all of the conditions remained unchanged and the major differences in cities 644 were in their different SCI-mobility curves. Finally, the estimated number of cases (in a 1-year 645 period) and duration of physical distancing were reported as indicators for the assessment. 
Extended Data

Extended Data Table 1. Example sets of physical distancing measures over different periods

652

\begin{tabular}{lll}
\hline $\begin{array}{l}\text { Physical } \\
\text { distancing } \\
\text { intensity }\end{array}$ & Period & Example set of measures \\
\hline No & $\begin{array}{l}\text { Pre-lockdown period } \\
\text { December 2019 }\end{array}$ & None \\
\hline Mild & $\begin{array}{l}\text { Longer after lockdown-lifting (LALDL) } \\
\text { May 20 - May 30, 2020 after nucleic acid } \\
\text { testing of all Wuhan citizens }\end{array}$ & $\begin{array}{l}\text { Closure of schools and a } \\
\text { 20\% reduction in contact } \\
\text { in all other categories }\end{array}$ \\
\hline & & $\begin{array}{l}\text { Closure of schools, an } 80 \% \\
\text { reduction in contact in } \\
\text { shopping/recreation, and a }\end{array}$ \\
& $\begin{array}{l}\text { Shortly after lockdown-lifting (SALDL) } \\
\text { April } 9 \text { - around May 20, 2020 reduction in contact } \\
\text { in all other categories }\end{array}$ \\
\hline & & $\begin{array}{l}\text { Only 50\% of the pre- } \\
\text { lockdown-level contact in } \\
\text { residential communities } \\
\text { and the closure of all other } \\
\text { non-essential facilities }\end{array}$ \\
\hline
\end{tabular}


655 Extended Data Table 2. Ro values and their corresponding herd immunity thresholds

\begin{tabular}{|c|c|c|c|c|}
\hline Study & Location & Study period & $\begin{array}{l}\text { Ro estimate } \\
\text { (average } \\
\text { value) }\end{array}$ & $\begin{array}{l}\text { Herd } \\
\text { immunity } \\
\text { threshold } \\
\left(1-1 / R_{0}\right)\end{array}$ \\
\hline Joseph et al. ${ }^{55}$ & Wuhan & $\begin{array}{l}\text { December } 31,2019- \\
\text { January } 28,2020\end{array}$ & 2.68 & 0.627 \\
\hline Shen et al. ${ }^{56}$ & $\begin{array}{l}\text { Hubei } \\
\text { province }\end{array}$ & January 12-22, 2020 & 6.49 & 0.846 \\
\hline Liu et al. ${ }^{57}$ & $\begin{array}{l}\text { China and } \\
\text { overseas }\end{array}$ & January 23, 2020 & 2.9 & 0.655 \\
\hline Liu et al. ${ }^{57}$ & $\begin{array}{l}\text { China and } \\
\text { overseas }\end{array}$ & January 23, 2020 & 2.92 & 0.658 \\
\hline Read et al. ${ }^{58}$ & China & January 1-22, 2020 & 3.11 & 0.678 \\
\hline Majumder et al. ${ }^{59}$ & Wuhan & $\begin{array}{l}\text { December 8, } 2019 \text { and } \\
\text { January 26, } 2020\end{array}$ & $2.0-3.1(2.55)$ & 0.608 \\
\hline WHO & China & January 18, 2020 & $1.4-2.5(1.95)$ & 0.487 \\
\hline Cao et al. ${ }^{60}$ & China & January 23,2020 & 4.08 & 0.755 \\
\hline Zhao et al. ${ }^{61}$ & China & January 10-24, 2020 & 2.24 & 0.554 \\
\hline Zhao et al. ${ }^{61}$ & China & January 10-24, 2020 & 3.58 & 0.721 \\
\hline Imai et al. ${ }^{62}$ & Wuhan & January 18,2020 & $1.5-3.5(2.5)$ & 0.600 \\
\hline Julien and Althaus ${ }^{63}$ & $\begin{array}{l}\text { China and } \\
\text { overseas }\end{array}$ & January 18, 2020 & 2.2 & 0.545 \\
\hline Tang et al. ${ }^{64}$ & China & January 22, 2020 & 6.47 & 0.845 \\
\hline Qun Li et al. ${ }^{1}$ & China & 2January 22, 2020 & 2.2 & 0.545 \\
\hline 25th quantile of $R_{0}$ & & & 2.30 & 0.566 \\
\hline 50th quantile of $R_{0}$ & & & 2.79 & 0.642 \\
\hline 75th quantile of $R_{0}$ & & & 4.36 & 0.711 \\
\hline
\end{tabular}


Extended Data Table 3. Short-term response of vaccines

\begin{tabular}{|c|c|c|c|c|}
\hline $\begin{array}{l}\text { Name of } \\
\text { vaccines }\end{array}$ & $\begin{array}{l}\text { Seroconver } \\
\text { sion rate } \\
(\%) \\
\end{array}$ & Group mark & $\begin{array}{c}\text { Testing } \\
\text { time } \\
\text { (n }^{\text {th }} \\
\text { day) }\end{array}$ & Platform \\
\hline $\begin{array}{l}\text { NCT0432 } \\
4606\end{array}$ & 100.00 & $5 \times 10^{10}$ viral particles; two doses. & 42 & $\begin{array}{l}\text { non- } \\
\text { replicating } \\
\text { viral vector }\end{array}$ \\
\hline $\begin{array}{l}\text { NCT0443 } \\
7875\end{array}$ & 100.00 & Gam-COVID-Vac & 42 & $\begin{array}{l}\text { non- } \\
\text { replicating } \\
\text { viral vector }\end{array}$ \\
\hline $\begin{array}{l}\text { NCT0443 } \\
7875\end{array}$ & 100.00 & Gam-COVID-Vac Lyo & 42 & $\begin{array}{l}\text { non- } \\
\text { replicating } \\
\text { viral vector }\end{array}$ \\
\hline $\begin{array}{l}\text { NCT0431 } \\
3127\end{array}$ & 50.00 & Low dose group $(n=36) / 4$-fold increase & 28 & adenovirus \\
\hline $\begin{array}{l}\text { NCT0431 } \\
3127\end{array}$ & 50.00 & Middle dose group $(n=36) / 4$-fold increase & 28 & adenovirus \\
\hline $\begin{array}{l}\text { NCT0431 } \\
3127\end{array}$ & 75.00 & High dose group $(n=36) / 4$-fold increase & 28 & adenovirus \\
\hline $\begin{array}{l}\text { NCT0432 } \\
4606\end{array}$ & 91.00 & $5 \times 10^{10}$ viral particles; one dose & 28 & $\begin{array}{l}\text { non- } \\
\text { replicating } \\
\text { viral vector }\end{array}$ \\
\hline $\begin{array}{l}\text { NCT0434 } \\
1389\end{array}$ & 59.00 & $\begin{array}{l}1 \times 10^{11} \text { viral particles dose group; } \\
\text { pseudovirus }\end{array}$ & 28 & $\begin{array}{l}\text { non- } \\
\text { replicating } \\
\text { viral vector }\end{array}$ \\
\hline $\begin{array}{l}\text { NCT0434 } \\
1389\end{array}$ & 47.00 & $\begin{array}{l}5 \times 10^{10} \text { viral particles dose group; } \\
\text { pseudovirus }\end{array}$ & 28 & $\begin{array}{l}\text { non- } \\
\text { replicating } \\
\text { viral vector }\end{array}$ \\
\hline $\begin{array}{l}\text { NCT0434 } \\
1389\end{array}$ & 59.00 & $\begin{array}{l}1 \times 10^{11} \text { viral particles dose group; live } \\
\text { SARS-CoV-2 }\end{array}$ & 28 & $\begin{array}{l}\text { non- } \\
\text { replicating } \\
\text { viral vector }\end{array}$ \\
\hline $\begin{array}{l}\text { NCT0434 } \\
1389\end{array}$ & 47.00 & $\begin{array}{l}5 \times 10^{10} \text { viral particles dose group; live } \\
\text { SARS-CoV-2 }\end{array}$ & 28 & $\begin{array}{l}\text { non- } \\
\text { replicating } \\
\text { viral vector }\end{array}$ \\
\hline $\begin{array}{l}\text { NCT0434 } \\
1389\end{array}$ & 59.00 & $\begin{array}{l}1 \times 10^{11} \text { viral particles dose group; live } \\
\text { SARS-CoV-2; pre-existing Ad5 }<=200\end{array}$ & 28 & $\begin{array}{l}\text { non- } \\
\text { replicating } \\
\text { viral vector }\end{array}$ \\
\hline $\begin{array}{l}\text { NCT0434 } \\
1389\end{array}$ & 47.00 & $\begin{array}{l}5 \times 10^{10} \text { viral particles dose group; live } \\
\text { SARS-CoV-2; pre-existing Ad5 }<=200\end{array}$ & 28 & $\begin{array}{l}\text { non- } \\
\text { replicating }\end{array}$ \\
\hline
\end{tabular}




\begin{tabular}{|c|c|c|c|c|}
\hline & & & & viral vector \\
\hline NCT0434 & & $1 \times 10^{11}$ viral particles dose group; live & & $\begin{array}{l}\text { non- } \\
\text { replicating }\end{array}$ \\
\hline 1389 & 59.00 & SARS-CoV-2; pre-existing Ad5>200 & 28 & viral vector \\
\hline NCT0434 & & $5 \times 10^{10}$ viral particles dose group; live & & $\begin{array}{l}\text { non- } \\
\text { replicating }\end{array}$ \\
\hline 1389 & 47.00 & SARS-CoV-2; pre-existing Ad5>200 & 28 & viral vector \\
\hline $\begin{array}{l}\text { NCT0434 } \\
1389\end{array}$ & 59.00 & $\begin{array}{l}1 \times 10^{11} \text { viral particles dose group; } \\
\text { pseudovirus; pre-existing } \operatorname{Ad} 5<=200\end{array}$ & 28 & $\begin{array}{l}\text { non- } \\
\text { replicating } \\
\text { viral vector }\end{array}$ \\
\hline $\begin{array}{l}\text { NCT0434 } \\
1389 \\
\end{array}$ & 47.00 & $\begin{array}{l}5 \times 10^{10} \text { viral particles dose group; } \\
\text { pseudovirus; pre-existing } \operatorname{Ad} 5<=200\end{array}$ & 28 & $\begin{array}{l}\text { non- } \\
\text { replicating } \\
\text { viral vector }\end{array}$ \\
\hline $\begin{array}{l}\text { NCT0434 } \\
1389 \\
\end{array}$ & 59.00 & $\begin{array}{l}1 \times 10^{11} \text { viral particles dose group; } \\
\text { pseudovirus; pre-existing } \operatorname{Ad} 5>200\end{array}$ & 28 & $\begin{array}{l}\text { non- } \\
\text { replicating } \\
\text { viral vector }\end{array}$ \\
\hline $\begin{array}{l}\text { NCT0434 } \\
1389\end{array}$ & 47.00 & $\begin{array}{l}5 \times 10^{10} \text { viral particles dose group; } \\
\text { pseudovirus; pre-existing } \operatorname{Ad} 5>200\end{array}$ & 28 & $\begin{array}{l}\text { non- } \\
\text { replicating } \\
\text { viral vector }\end{array}$ \\
\hline \multicolumn{5}{|l|}{ NCT0435 } \\
\hline 2608 & 97.40 & $3 \mu \mathrm{g} / 0.5 \mathrm{ml}$ & 28 & inactivated \\
\hline $\begin{array}{l}\text { NCT0443 } \\
7875\end{array}$ & 66.70 & Gam-COVID-Vac; rAd26-S & 28 & $\begin{array}{l}\text { non- } \\
\text { replicating } \\
\text { viral vector }\end{array}$ \\
\hline $\begin{array}{l}\text { NCT0443 } \\
7875\end{array}$ & 66.70 & Gam-COVID-Vac; rAd5-S & 28 & $\begin{array}{l}\text { non- } \\
\text { replicating } \\
\text { viral vector }\end{array}$ \\
\hline $\begin{array}{l}\text { NCT0443 } \\
7875\end{array}$ & 55.60 & Gam-COVID-Vac Lyo; rAd26-S & 28 & $\begin{array}{l}\text { non- } \\
\text { replicating } \\
\text { viral vector }\end{array}$ \\
\hline $\begin{array}{l}\text { NCT0443 } \\
7875\end{array}$ & 88.90 & Gam-COVID-Vac Lyo; rAd5-S & 28 & $\begin{array}{l}\text { non- } \\
\text { replicating } \\
\text { viral vector }\end{array}$ \\
\hline $\begin{array}{l}\text { ChiCTR2 } \\
00003180\end{array}$ & & & & \\
\hline 9 & 97.60 & Medium dose & 14 & inactivated \\
\hline NCT0431 & & & & \\
\hline 3127 & 28.00 & Low dose group & 14 & adenovirus \\
\hline NCT0431 & & & & \\
\hline 3127 & 31.00 & Middle dose group & 14 & adenovirus \\
\hline
\end{tabular}




\begin{tabular}{|c|c|c|c|c|}
\hline $\begin{array}{l}\text { NCT0431 } \\
3127\end{array}$ & 42.00 & High dose group & 14 & adenovirus \\
\hline \multicolumn{5}{|l|}{ NCT0435 } \\
\hline 2608 & 92.40 & $3 \mu \mathrm{g} / 0.5 \mathrm{ml}$ & 14 & inactivated \\
\hline NCT0443 & & & & $\begin{array}{l}\text { non- } \\
\text { replicating }\end{array}$ \\
\hline 7875 & 55.60 & Gam-COVID-Vac; rAd26-S & 14 & viral vector \\
\hline $\begin{array}{l}\text { NCT0443 } \\
7875\end{array}$ & 55.60 & Gam-COVID-Vac; rAd5-S & 14 & $\begin{array}{l}\text { non- } \\
\text { replicating } \\
\text { viral vector }\end{array}$ \\
\hline $\begin{array}{l}\text { NCT0443 } \\
7875\end{array}$ & 22.20 & Gam-COVID-Vac Lyo; rAd26-S & 14 & $\begin{array}{l}\text { non- } \\
\text { replicating } \\
\text { viral vector }\end{array}$ \\
\hline $\begin{array}{l}\text { NCT0443 } \\
7875\end{array}$ & 66.70 & Gam-COVID-Vac Lyo; rAd5-S & 14 & $\begin{array}{l}\text { non- } \\
\text { replicating } \\
\text { viral vector }\end{array}$ \\
\hline
\end{tabular}

659

660 
661 Extended Data Table 4. Validation result of joint vaccination and physical distancing measures 662 in six other cities

\begin{tabular}{|c|c|c|c|c|c|}
\hline $\begin{array}{l}\text { Physical } \\
\text { distancing }\end{array}$ & $\begin{array}{l}\text { Infected cases in one year } \\
\qquad(95 \% \mathrm{CI})\end{array}$ & $\begin{array}{c}\text { Reduction } \\
\text { rate of } \\
\text { cases }^{\mathrm{a}} \\
\end{array}$ & $\begin{array}{c}\text { Duration under } \\
\text { physical } \\
\text { distancing }\end{array}$ & City & $\begin{array}{l}\text { Popula } \\
\text { tion } \\
\text { density } \\
\end{array}$ \\
\hline No & $7(1-20)$ & - & - & \multirow{4}{*}{ Qiqihar } & \multirow{4}{*}{130.28} \\
\hline Mild & $7(1-18)$ & - & $0(0-0)$ & & \\
\hline Moderate & $7(1-20)$ & - & $0(0-0)$ & & \\
\hline Strong & $8(2-21)$ & - & $0(0-0)$ & & \\
\hline No & $181(26-524)$ & - & - & \multirow{4}{*}{ Zhuzhou } & \multirow{4}{*}{355.7} \\
\hline Mild & $171(17-497)$ & - & $0(0-2)$ & & \\
\hline Moderate & $120(18-488)$ & - & $0(0-0)$ & & \\
\hline Strong & $146(21-473)$ & - & $0(0-0)$ & & \\
\hline No & $47(9-189)$ & - & - & \multirow{4}{*}{$\begin{array}{c}\text { Wuhan's } \\
\text { low- } \\
\text { density } \\
\text { scenario }\end{array}$} & \multirow{4}{*}{338.4} \\
\hline Mild & $54(11-196)$ & - & $0(0-0)$ & & \\
\hline Moderate & $49(11-194)$ & - & $0(0-0)$ & & \\
\hline Strong & $59(16-218)$ & - & $0(0-0)$ & & \\
\hline No & $1538(22-3271)$ & - & - & \multirow{4}{*}{ Hangzhou } & \multirow{4}{*}{561.78} \\
\hline Mild & $799(21-1330)$ & $48.03 \%$ & $129(0-225)$ & & \\
\hline Moderate & $330(20-538)$ & $78.52 \%$ & $57(0-101)$ & & \\
\hline Strong & $237(21-625)$ & $84.60 \%$ & $29(0-40)$ & & \\
\hline No & $10441(3648-20569)$ & - & - & \multirow{4}{*}{ Hefei } & \multirow{4}{*}{715.5} \\
\hline Mild & $1392(32-2144)$ & $86.66 \%$ & $214(0-270)$ & & \\
\hline Moderate & $380(212-583)$ & $96.36 \%$ & $80(47-122)$ & & \\
\hline Strong & $221(84-332)$ & $97.88 \%$ & $34(0-45)$ & & \\
\hline No & $6894(1302-11565)$ & - & - & \multirow{4}{*}{$\begin{array}{c}\text { Wuhan's } \\
\text { medium- } \\
\text { density } \\
\text { scenario }\end{array}$} & \multirow{4}{*}{564} \\
\hline Mild & $776(368-1064)$ & $88.74 \%$ & $163(90-242)$ & & \\
\hline Moderate & $298(130-438)$ & $95.68 \%$ & $55(35-80)$ & & \\
\hline Strong & $205(94-347)$ & $97.02 \%$ & $29(0-45)$ & & \\
\hline No & $10.23 \%(9.21 \%-10.85 \%)^{b}$ & - & - & \multirow{4}{*}{ Chengdu } & \multirow{4}{*}{1123} \\
\hline Mild & $2.15 \%(1.25 \%-2.92 \%)^{b}$ & $78.95 \%$ & $350(335-355)$ & & \\
\hline Moderate & $5353(3285-8368)$ & $99.95 \%$ & $278(240-310)$ & & \\
\hline Strong & $251(152-417)$ & $99.99 \%$ & $53(39-81)$ & & \\
\hline No & $10.23 \%(8.14 \%-11.11 \%)^{b}$ & - & - & \multirow{4}{*}{ Beijing } & \multirow{4}{*}{1312} \\
\hline Mild & $3.11 \%(1.55 \%-3.93 \%)^{\mathrm{b}}$ & $69.63 \%$ & $347(326-354)$ & & \\
\hline Moderate & 4297 (2062-6437) & $99.96 \%$ & $261(215-302)$ & & \\
\hline Strong & $209(116-310)$ & $99.99 \%$ & $40(30-57)$ & & \\
\hline No & $17.72 \%(16.26 \%-18.74 \%)^{b}$ & - & - & \multirow{2}{*}{$\begin{array}{l}\text { Wuhan's } \\
\text { high- }\end{array}$} & \multirow{2}{*}{1128} \\
\hline Mild & $0.40 \%(0.22 \%-0.60 \%)^{\mathrm{b}}$ & $97.72 \%$ & $350(338-354)$ & & \\
\hline
\end{tabular}




\begin{tabular}{ccccc} 
Moderate & $1800(991-2821)$ & $99.99 \%$ & $234(166-295)$ & density \\
Strong & $213(122-347)$ & $99.99 \%$ & $43(33-64)$ & scenario \\
\hline
\end{tabular}

a The reduction rate of cases refers to the percentage of cases that could be reduced if a physical distancing intensity (listed on the left) were applied compared with a no physical distancing scenario. The no physical distancing scenario and the scenarios with a very limited number of cases that do not require physical distancing are marked as "-.." (about 107.83, 112.79, and 102.25 million in Chengdu, Beijing, and Wuhan, respectively) given a so large number; see Methods "Estimation of population migration and associated population density variations" for more details. 
A

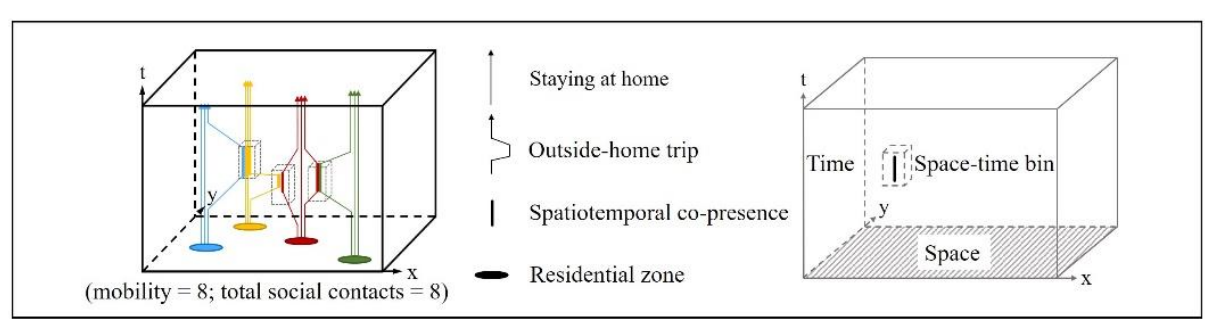

B

Total social contacts

(Number of spatiotemporal co-presences)

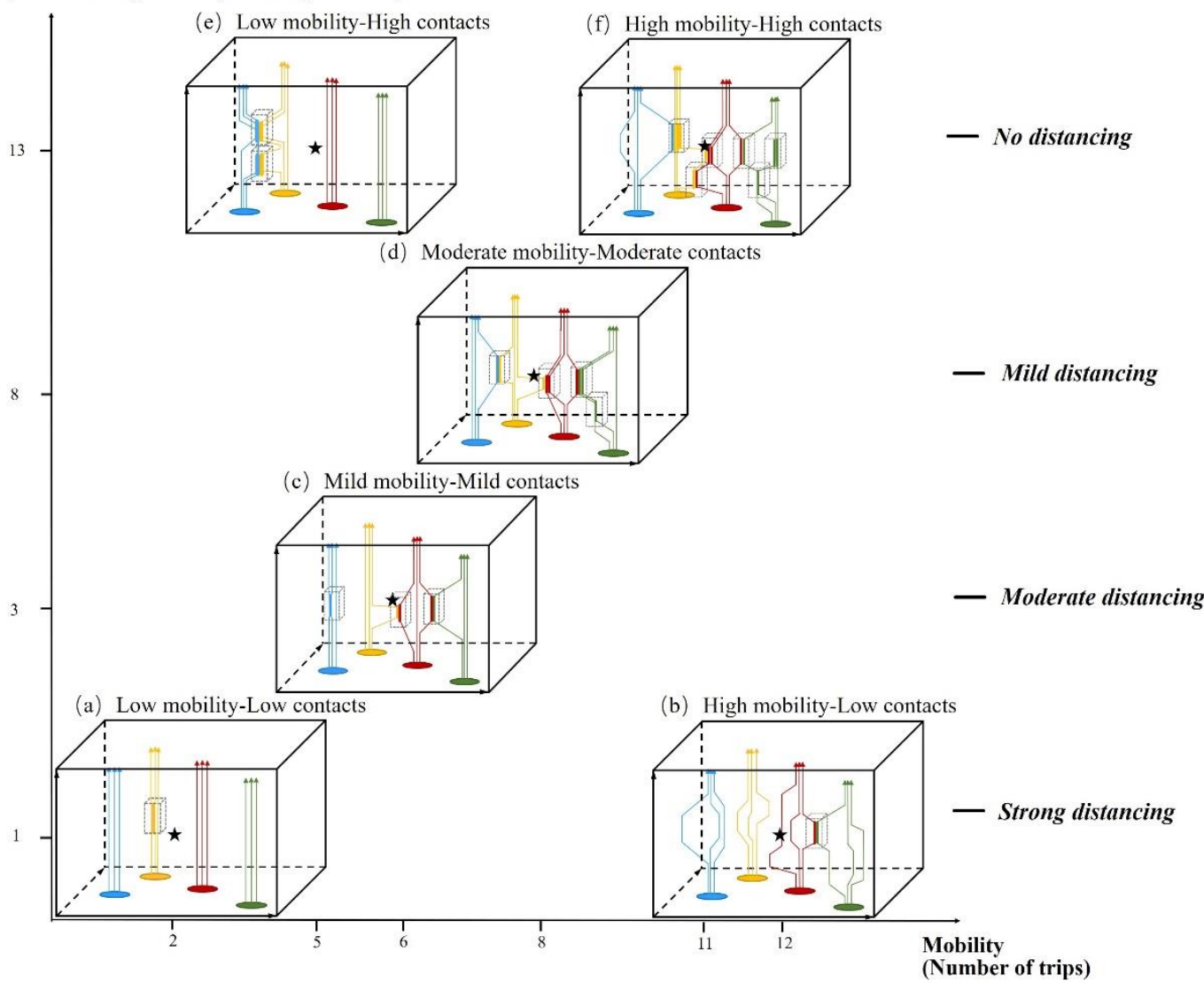

Extended Data Fig 1. Mobility-derived social contacts in the form of spatiotemporal co-presence. (A) The colored arrowed lines within a space-time cube represent the daily travel routes of citizens. The straight arrowed lines denote persons staying home. The polylines represent trips across several places. The colored ellipses represent residential zones. A person may encounter another person within a specified space-time bin, leading to spatiotemporal co-presence (or contact event). The number of outside-home trips (mobility) and total social contacts are thus derived and displayed below the left space-time cube. (B) The total social contacts in cubes (a), (c), (d), and (f) increase with increasing movement of people (represented by more polylines or a polyline with more line segments) and greater relaxation of physical distancing measures, from "strong," to "moderate," "mild," and "no." Cubes (a) and (b) show different mobility levels but similar levels of social contact. The physical distances between people in (b) are generally larger than those in (a), although they are under the same level of "strong distancing." Cubes (a) and (e) show similar 
686 levels of mobility but different levels of social contact and physical distancing. The change patterns 687 of mobility and social contact in the six space-time cubes reveal that the intensity of physical 688 distancing cannot be solely determined by social contact or mobility levels but by the relationship 689 between the two factors. 


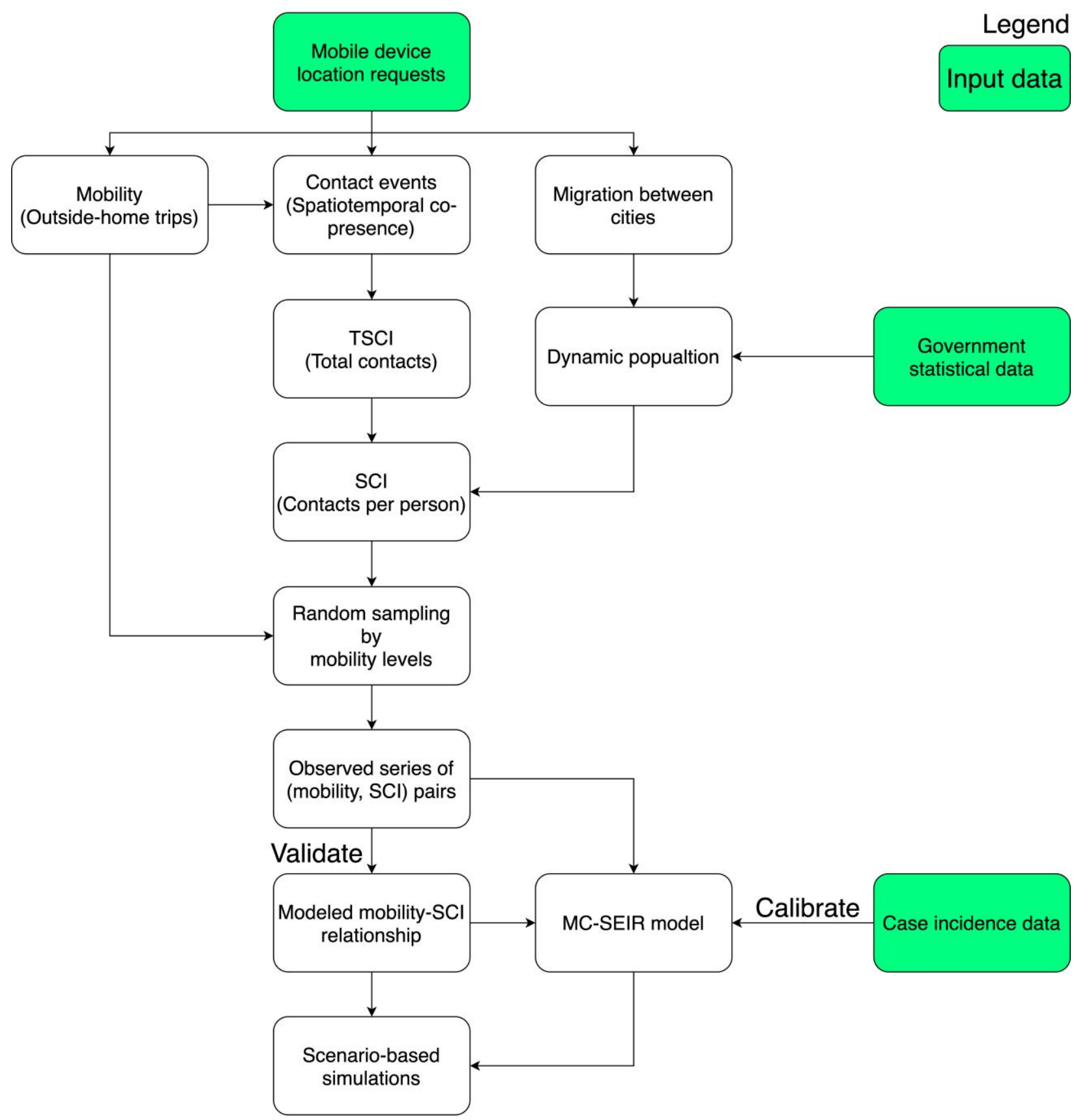

Extended Data Fig. 2. Calculation of the social contact index (SCI) and its link with the models and simulations in this study. 

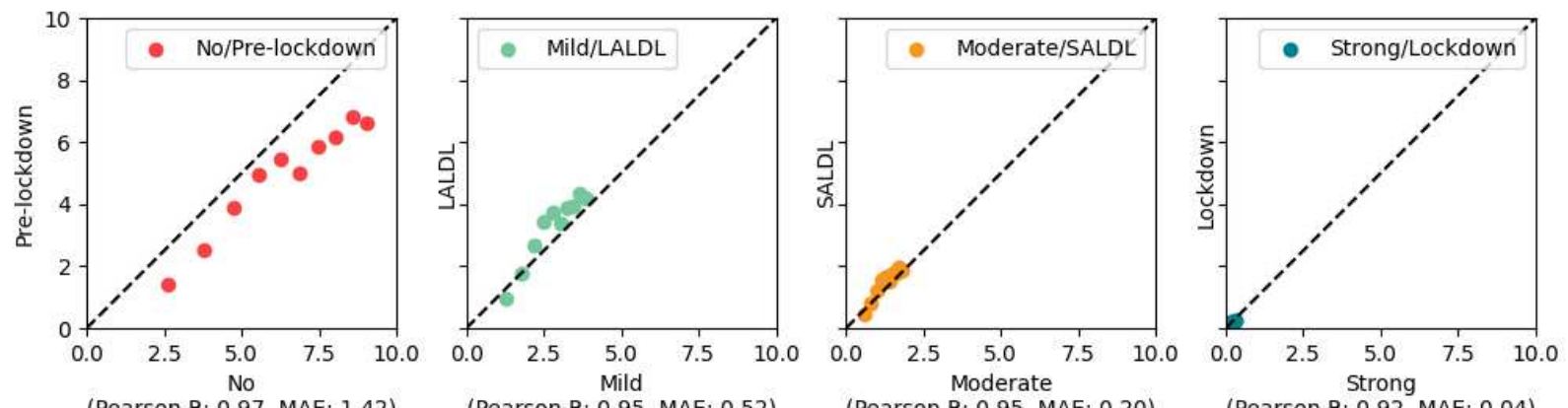

Extended Data Fig. 3. Comparisons of modeled and observed social contact index values under varying physical distancing intensities over different periods.
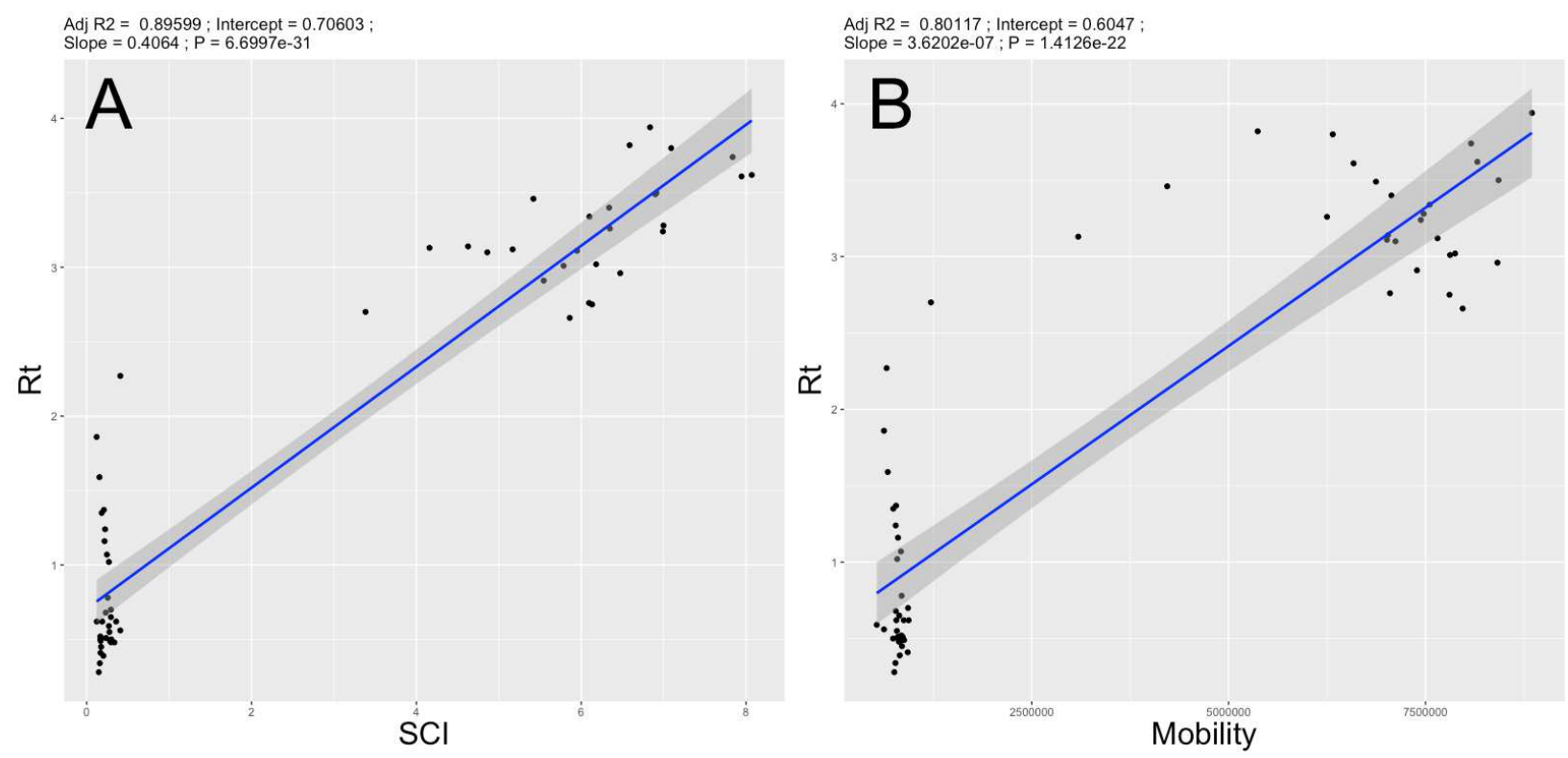

Extended Data Fig. 4. Comparison of the correlations between the social contact index (SCI) and (95\% CI: 71\%-89\%; $p<0.0001)$. 


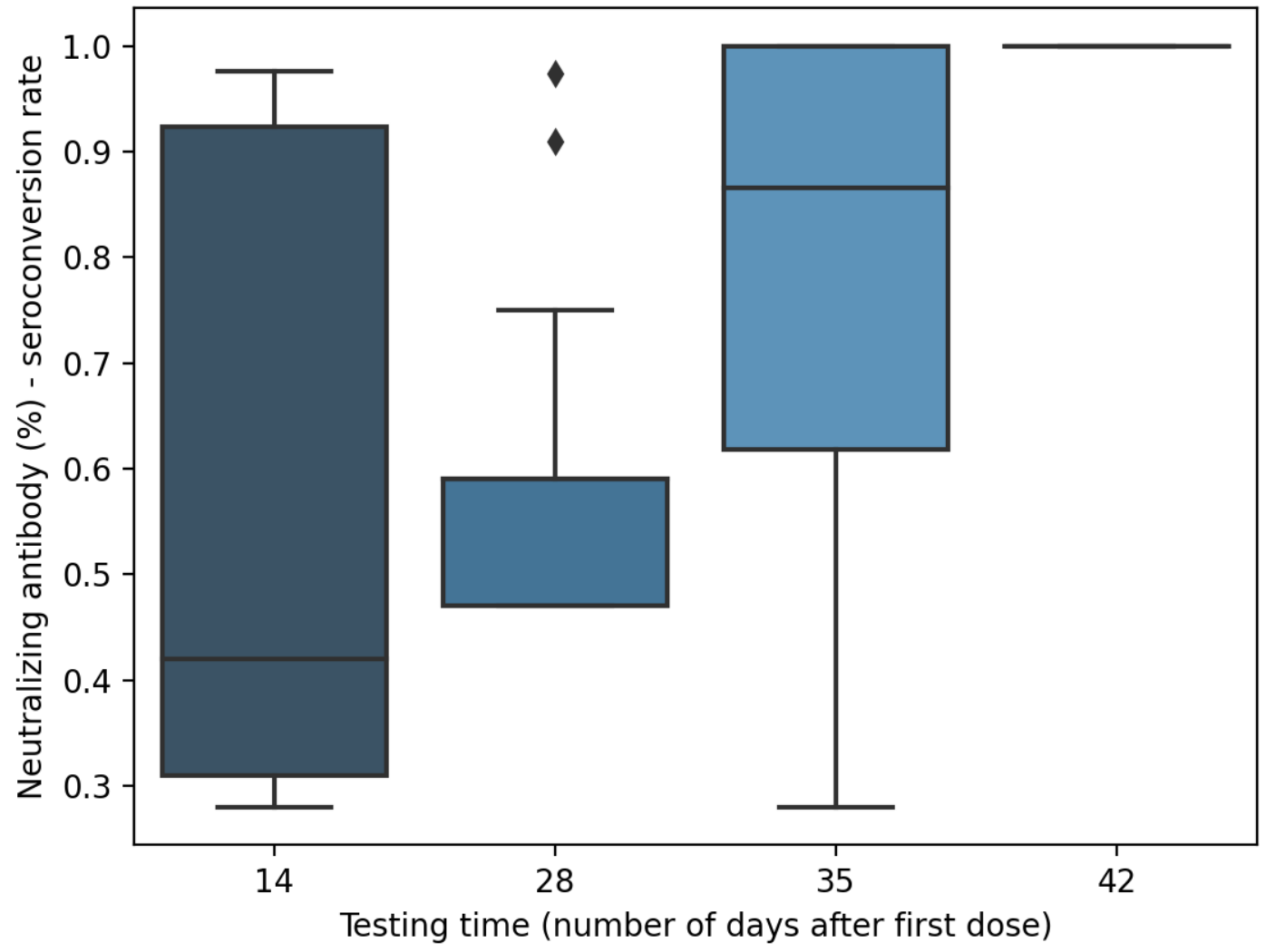

710 Extended Data Fig. 5. Effectiveness of vaccines. The seroconversion rates ( $y$-axis) of different 711 vaccine trials are reported and grouped by the number of days ( $x$-axis) after the first dose.

712

713 


\section{References}

1. Li, Q. et al. Early transmission dynamics in Wuhan, China, of novel coronavirus-infected pneumonia. N. Engl. J. Med. 382, 1199-1207 (2020).

2. World Health Organization. Coronavirus disease (COVID-19) - World Health Organization. https://www.who.int/emergencies/diseases/novel-coronavirus-2019 (2020)

3. Guan, D. et al. Global supply-chain effects of COVID-19 control measures. Nat Hum Behav 4, 577-587 (2020).

4. de Souza, W. M. et al. Epidemiological and clinical characteristics of the COVID-19 epidemic in Brazil. Nat Hum Beh 4, 856-865 (2020).

5. Kissler, S. M., Tedijanto, C., Goldstein, E., Grad, Y. H. \& Lipsitch, M. Projecting the transmission dynamics of SARS-CoV-2 through the postpandemic period. Science 368, 860868 (2020).

6. López, L. \& Rodó, X. The end of social confinement and COVID-19 re-emergence risk. Nat Hum Behav 4, 746-755 (2020).

7. Wong, M. C. S. et al. Stringent containment measures without complete city lockdown to achieve low incidence and mortality across two waves of COVID-19 in Hong Kong. BMJ Glob Health 5, (2020).

8. Bonaccorsi, G. et al. Economic and social consequences of human mobility restrictions under COVID-19. Proc. Natl. Acad. Sci. USA. 117, 15530-15535 (2020).

9. The DELVE Initiative. SARS-CoV-2 Vaccine Development \& Implementation; Scenarios, Options, Key Decisions. http://rs-delve.github.io/reports/2020/10/01/covid19-vaccinationreport.html (2020) (accessed 5 November 2020).

10. Quer, G. et al. Wearable sensor data and self-reported symptoms for COVID-19 detection. Nat. Med. 1-5 (2020) doi:10.1038/s41591-020-1123-x.

11. Iqbal, M. WeChat Revenue and Usage Statistics (2020). https://www.businessofapps.com/data/wechat-statistics/ (2020) (accessed 5 November 2020).

12. Le, T. T., Cramer, J. P., Chen, R. \& Mayhew, S. Evolution of the COVID-19 vaccine development landscape. Nat Rev Drug Discov 19, 667-668 (2020).

13. Wesolowski, A. et al. Quantifying the impact of human mobility on malaria. Science 338, 267270 (2012).

14. González, M. C., Hidalgo, C. A. \& Barabási, A.-L. Understanding individual human mobility patterns. Nature 453, 779-782 (2008).

15. Wesolowski, A. et al. Multinational patterns of seasonal asymmetry in human movement influence infectious disease dynamics. Nat. Commun. 8, 2069 (2017).

16. Lai, S. et al. Exploring the use of mobile phone data for national migration statistics. Palgrave Commun 5, (2019).

17. Ruktanonchai, N. W. et al. Assessing the impact of coordinated COVID-19 exit strategies across Europe. Science (2020) doi:10.1126/science.abc5096. 
18. Prem, K. et al. The effect of control strategies to reduce social mixing on outcomes of the COVID-19 epidemic in Wuhan, China: a modelling study. Lancet Public Health 5, e261-e270 (2020).

19. Budd, J. et al. Digital technologies in the public-health response to COVID-19. Nat. Med. 26, 1183-1192 (2020).

20. Buckee, C. O. et al. Aggregated mobility data could help fight COVID-19. Science 368, 145146 (2020).

21. Oliver, N. et al. Mobile phone data for informing public health actions across the COVID-19 pandemic life cycle. Sci Adv 6, eabc0764 (2020).

22. Jia, J. S. et al. Population flow drives spatio-temporal distribution of COVID-19 in China. Nature 582, 389-394 (2020).

23. Zhang, J. et al. Changes in contact patterns shape the dynamics of the COVID-19 outbreak in China. Science 368, 1481-1486 (2020).

24. Lai, S. et al. Effect of non-pharmaceutical interventions to contain COVID-19 in China. Nature (2020).

25. Kraemer, M. U. G. et al. The effect of human mobility and control measures on the COVID19 epidemic in China. Science 368, 493-497 (2020).

26. Hsiang, S. et al. The effect of large-scale anti-contagion policies on the COVID-19 pandemic. Nature 584, 262-267 (2020).

27. Tian, H. et al. An investigation of transmission control measures during the first 50 days of the COVID-19 epidemic in China. Science 368, 638-642 (2020).

28. Gao, S. et al. Mobile phone location data reveal the effect and geographic variation of social distancing on the spread of the COVID-19 epidemic. Preprint at arXiv http://arxiv.org/abs/2004.11430 (2020).

29. Nouvellet, P. et al. Report 26: Reduction in mobility and COVID-19 transmission. http://spiral.imperial.ac.uk/handle/10044/1/79643 (2020) doi:10.25561/79643 (accessed 5 November 2020).

30. Badr, H. S. et al. Association between mobility patterns and COVID-19 transmission in the USA: a mathematical modelling study. The Lancet Infectious Diseases (2020) doi:10.1016/S1473-3099(20)30553-3 (accessed 5 November 2020).

31. Baidu. Baidu Migration. https://qianxi.baidu.com/ (accessed 5 November 2020).

32. Google. COVID-19 Community Mobility Reports. https://www.google.com/covid19/mobility (accessed 5 Novermber 2020).

33. Facebook. Our Work on COVID-19 - Facebook Data for Good. https://dataforgood.fb.com/docs/covid19/ (accessed 5 Novermber 2020).

34. Tencent. Tencent Big Data Platform. https://heat.qq.com/ (accessed 5 Novermber 2020).

35. Allen, W. E. et al. Population-scale longitudinal mapping of COVID-19 symptoms, behaviour and testing. Nat Hum Behav 4, 972-982 (2020).

36. Reiner, R. C. et al. Modeling COVID-19 scenarios for the United States. Nat Med 1-12 (2020) doi:10.1038/s41591-020-1132-9. 
37. Chowell, G., Hyman, J. M., Eubank, S. \& Castillo-Chavez, C. Scaling laws for the movement of people between locations in a large city. Phys. Rev. E Stat. Nonlin. Soft Matter Phys. 68, 066102 (2003).

38. Hägerstrand, T. What about people in Regional Science? Papers of the Regional Science Association 24, 6-21 (1970).

39. Kwan, M. GIS methods in time-geographic research: geocomputation and geovisualization of human activity patterns. Geografiska Annaler: Series B, Human Geography 86, 267-280 (2004).

40. Yin, L. \& Shaw, S.-L. Exploring space-time paths in physical and social closeness spaces: a space-time GIS approach. International Journal of Geographical Information Science 29, 742-761 (2015).

41. Hao, X. et al. Reconstruction of the full transmission dynamics of COVID-19 in Wuhan (2020) Nature 584, 420-424 (2020) (accessed 5 Novermber 2020).

42. Bergstra, J. S., Bardenet, R., Bengio, Y. \& Kégl, B. Algorithms for Hyper-Parameter Optimization. in Advances in Neural Information Processing Systems 2546-2554 (2011).

43. Flaxman, S. et al. Estimating the effects of non-pharmaceutical interventions on COVID-19 in Europe. Nature (2020) doi:10.1038/s41586-020-2405-7.

44. Walker, P. G. T. et al. The impact of COVID-19 and strategies for mitigation and suppression in low- and middle-income countries. Science (2020), 413-422 (2020).

45. Tsang, T. K. et al. Effect of changing case definitions for COVID-19 on the epidemic curve and transmission parameters in mainland China: a modelling study. Lancet Public Health $\mathbf{5}$, e289-e296 (2020).

46. Chu, D. K. et al. Physical distancing, face masks, and eye protection to prevent person-toperson transmission of SARS-CoV-2 and COVID-19: a systematic review and meta-analysis. Lancet 395, 1973-1987 (2020).

47. Li, Z. et al. Active case finding with case management: the key to tackling the COVID-19 pandemic. Lancet 396, 63-70 (2020).

48. Wuhan City Bureau of Statistics, Wuhan's national economic, social development statistical yearbook of 2019 (September 14, 2020).

49. National Bureau of Statistics of China, China statistical yearbook, http://www.stats.gov.cn/tjsj/tjgb/ndtjgb/ (September 14, 2020).

50. Kirkeby, C., Halasa, T., Gussmann, M., Toft, N. \& Græsbøll, K. Methods for estimating disease transmission rates: Evaluating the precision of Poisson regression and two novel methods. Sci Rep 7, (2017).

51. Pan, A. et al. Association of public health interventions with the epidemiology of the COVID19 outbreak in Wuhan, China. JAMA 323, 1915-1923 (2020).

52. Liu, Y., Gayle, A. A., Wilder-Smith, A. \& Rocklöv, J. The reproductive number of COVID19 is higher compared to SARS coronavirus. J Travel Med 27, (2020).

53. Lin, Q., Zhu, L., Ni, Z., Meng, H. \& You, L. Duration of serum neutralizing antibodies for SARS-CoV-2: Lessons from SARS-CoV infection. J Microbiol Immunol Infect 53, 821-822 (2020). 
54. Song, J. Y. et al. Long-term immunogenicity of influenza vaccine among the elderly: Risk factors for poor immune response and persistence. Vaccine 28, 3929-3935 (2010).

55. Wu, J. T., Leung, K. \& Leung, G. M. Nowcasting and forecasting the potential domestic and international spread of the 2019-nCoV outbreak originating in Wuhan, China: a modelling study. The Lancet 395, 689-697 (2020).

56. Shen, M., Peng, Z., Xiao, Y. \& Zhang, L. Modelling the epidemic trend of the 2019 novel coronavirus outbreak in China. (2020) doi:10.1101/2020.01.23.916726.

57. Liu, T., Hu, J. \& Kang, M. Transmission dynamics of 2019 novel coronavirus (2019-nCoV). bioRxiv 2020. https://doi.org/10.1101/2020.01.25.919787 (October 13, 2020).

58. Read, J. M., Bridgen, J. R., Cummings, D. A., Ho, A. \& Jewell, C. P. Novel coronavirus 2019nCoV: early estimation of epidemiological parameters and epidemic predictions. medRxiv 2020.01.23.20018549 (2020).

59. Majumder, M. S. \& Mandl, K. D. Early Transmissibility Assessment of a Novel Coronavirus in Wuhan, China. (2020) doi:10.2139/ssrn.3524675.

60. Estimating the effective reproduction number of the 2019-nCoV in China. medRxiv 2020. https://doi.org/10.1101/2020.01.27.20018952

61. Zhao, S. et al. Preliminary estimation of the basic reproduction number of novel coronavirus (2019-nCoV) in China, from 2019 to 2020: A data-driven analysis in the early phase of the outbreak. Int J Infect Dis 92, 214-217 (2020).

62. Imai, N. et al. Report 3: Transmissibility of 2019-nCoV. (Imperial College London, 2020) WHO Collaborating Centre for Infectious Disease Modelling, MRC Centre for Global Infectious Disease Analysis, J-IDEA, Imperial College London, UK. (October 13, 2020).

63. Riou, J. \& Althaus, C. L. Pattern of early human-to-human transmission of Wuhan 2019 novel coronavirus (2019-nCoV), December 2019 to January 2020. Euro Surveill 25, (2020).

64. Tang, B. et al. Estimation of the Transmission Risk of the 2019-nCoV and Its Implication for Public Health Interventions. J Clin Med 9, (2020).

\section{Competing interests}

The authors declare no competing interests. 


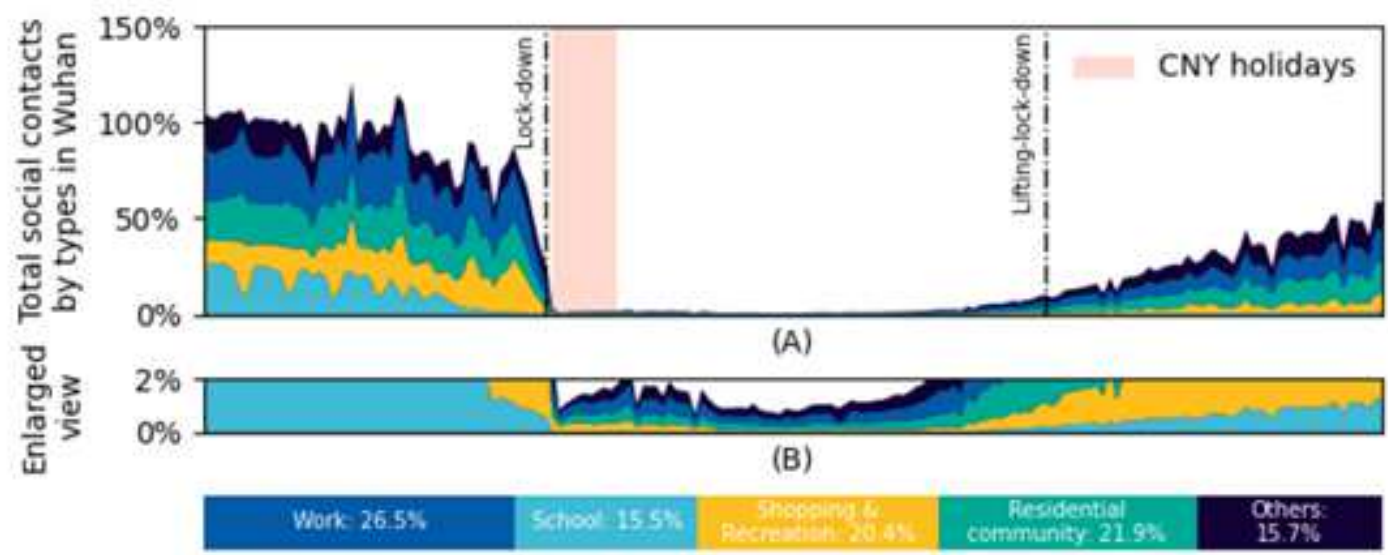

(C)

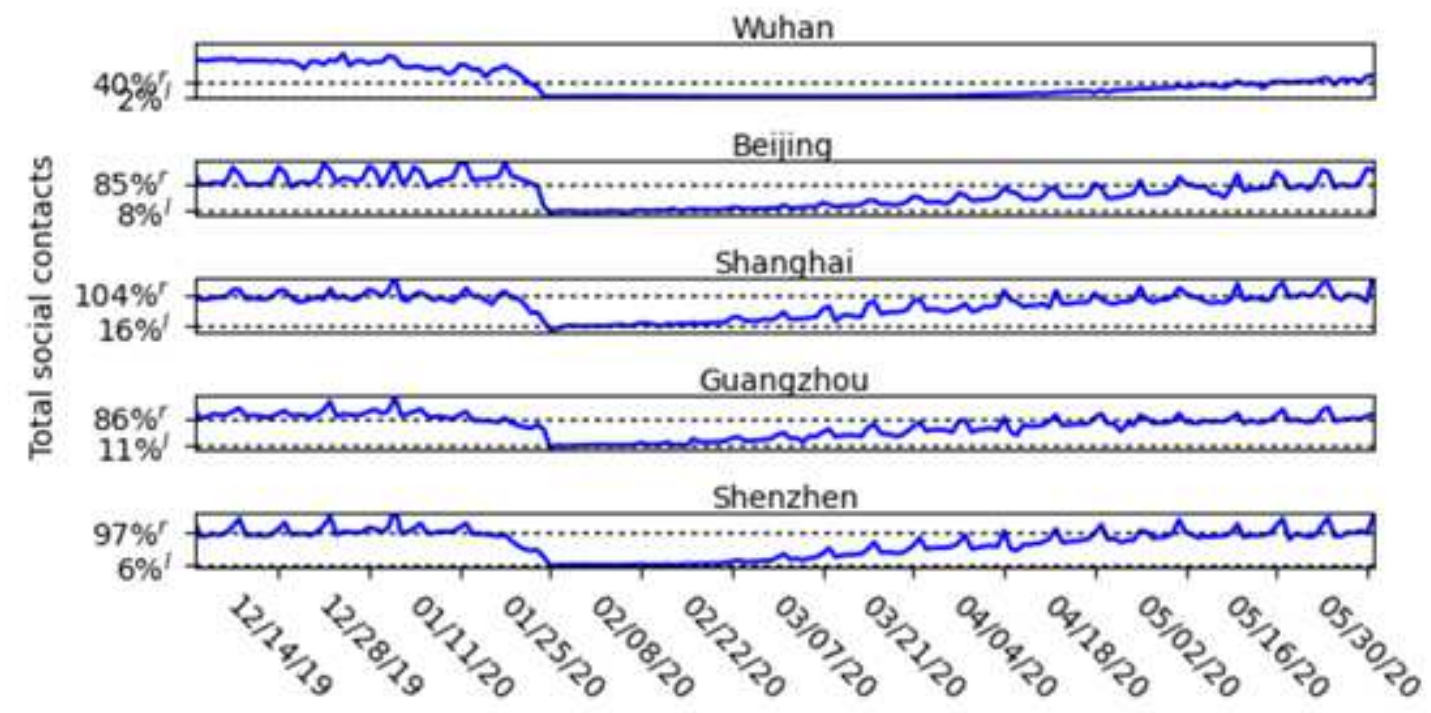

(D)

\section{Figure 1}

Change in total social contacts index (TSCI) in Wuhan and four other major cities in China (Beijing, Shanghai, Guangzhou, and Shenzhen). (A) Change of TSCI in Wuhan from December 2019 through May 2020 in the form of a percentage of the average pre-lockdown level in December 2019 (100\%). (B) The enlarged view of (A) on the part of TSCI between $0 \%$ and $2 \%$. (C) The proportions of TSCI that occurred in different colored categories of places in December 2019. Different colors in (A) and (B) represent the same as those in (C). (D) The change of TSCI in the five cities. "r" denotes the pre-lockdown TSCI that the city restored to post-lockdown and "I" the pre-lockdown TSCI that the city decreased to during the lockdown. The two vertical lines in $(\mathrm{A})$ denoting the lockdown and lockdown-lifting dates are only applicable to Wuhan as other cities announced the two dates differently. 


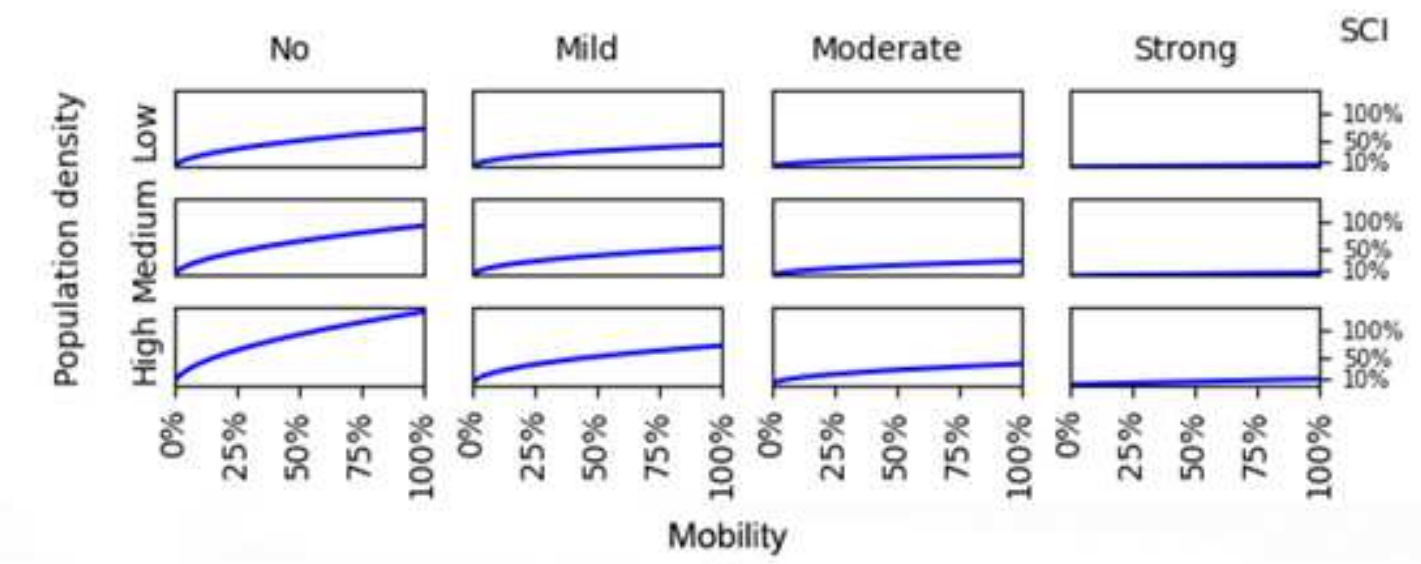

(A)

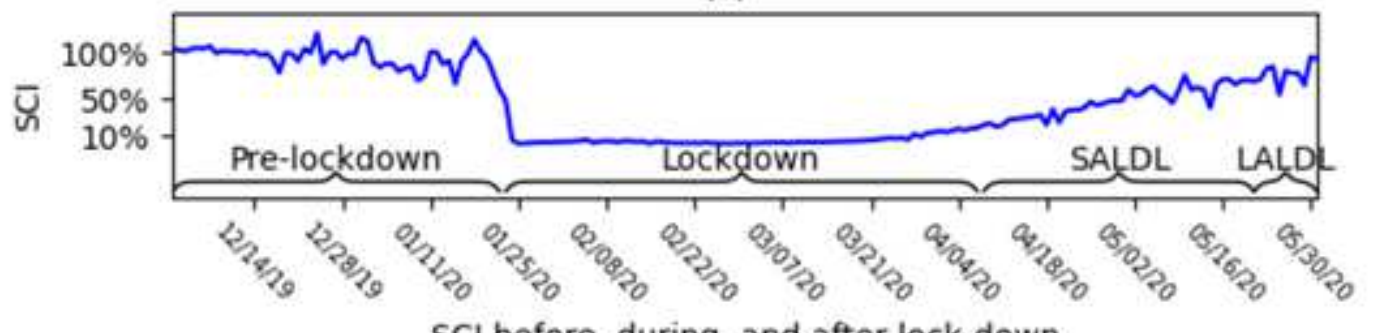

$\mathrm{SCl}$ before, during, and after lock-down

(B)

\section{Figure 2}

Change in the mobility - social contact index (SCl) relationship in Wuhan under different levels of population density and physical distancing. (A) Each chart shows the changing trend of $\mathrm{SCl}$ (in the form a percentage of the averaged pre-lockdown $\mathrm{SCl}$ ) over the mobility level increasing from $0 \%$ (no population movement), to $25 \%, 50 \%$, and finally $100 \%$ (no stay-at-home order) under a certain population density (low, medium, or high) for a specific intensity of physical distancing (none, mild, moderate, or strong). The four columns of charts from left to right are denoted with varying intensities of physical distancing imposed during different periods in Wuhan, i.e., pre-lockdown, LALDL, SALDL, and lockdown, respectively. (B) The daily change of SCI (in the form of a percentage of the averaged pre-lockdown SCl) in Wuhan from December 2019 through May 2020. 


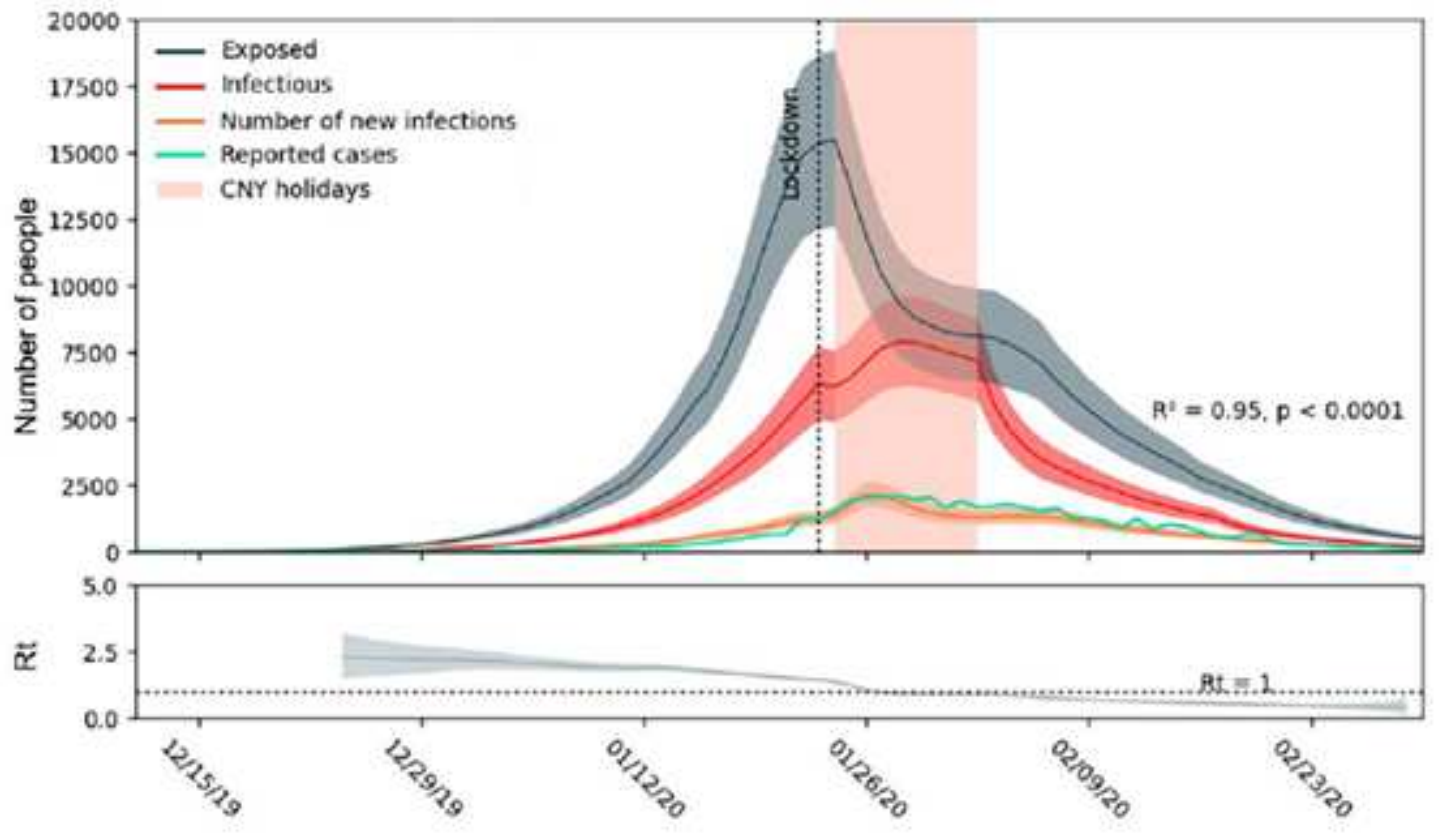

Figure 3

Fitted curves and Was predicted by the mobility and contact-based SEIR model. From top to bottom, the three curves in the upper chart represent the estimation of the daily exposed, infectious, and number of new infections from December 2019 through March 2020. The number of new infections examined against the daily reported cases yields the R2 of 0.95 at the statistical significance level of 0.0001 . The corresponding daily $\mathbb{\square}$ over the same period is displayed in the lower panel. 


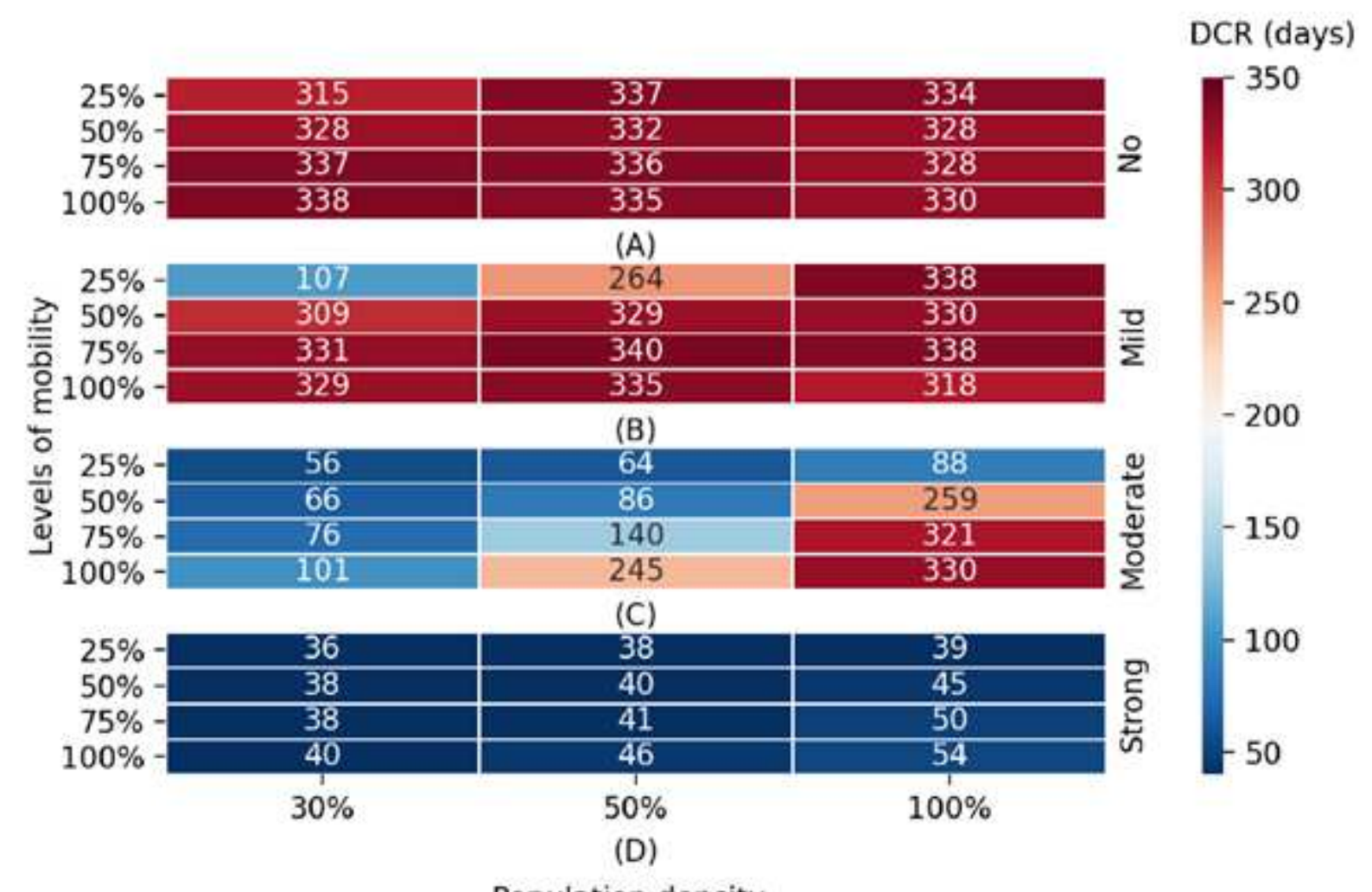

Population density

\section{Figure 4}

Estimated effects of control measures on containing a resurgence of infections under different population densities. (A)-(D) show for four intensities of physical distancing (i.e., none, mild, moderate, and strong), respectively, the median duration required to contain a resurgence (DCR, unit: days) in Wuhan with four levels of pre-lockdown mobility $(25 \%, 50 \%, 75 \%$, and $100 \%)$ under different population densities. The value in each cell denotes the DCR with respect to its associated level of mobility, intensity of physical distancing, and population density. The population densities are $30 \%, 50 \%$, and $100 \%$, respectively, of that in Wuhan pre-lockdown. 

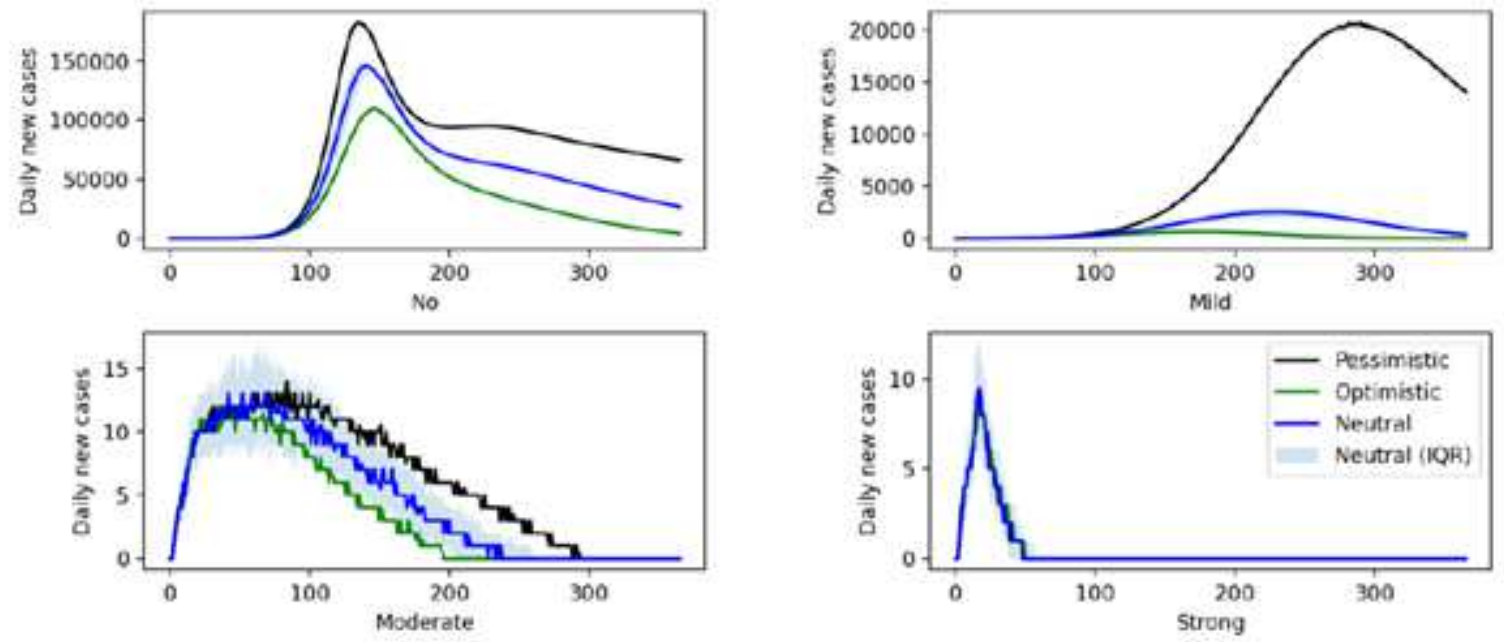

Figure 5

Joint effects of vaccination and physical distancing under optimistic, pessimistic, and neutral scenarios. The daily new case curves are plotted under the vaccination and physical distancing intensities. The $x$ axis represents the daily new cases and the $y$-axis represents the number of days since the start of the simulation. For the neutral scenario, the $25 \%$ and $75 \% 316$ quantiles of the daily cases are also displayed. 